\title{
Identification of Core Predication-Related Candidate Genes in Ovarian Cancer Based on Integrated Bioinformatics and Experienment
}

\section{Jiaqing Bi}

Shanxi Medical University https://orcid.org/0000-0003-0440-9025

Qian Qin

Shanxi Medical University

Huihan Ma

Shanxi Medical University

Meijie Ma

Shanxi Medical University

Qinmei Feng ( $\nabla$ qinmei_feng@163.com )

Shanxi Medical University

\section{Research}

Keywords: TTK, bioinformatics, Epithelial ovarian cancer, Immunohistochemistry, prediction

Posted Date: August 3rd, 2021

DOI: https://doi.org/10.21203/rs.3.rs-757589/v1

License: (1) (1) This work is licensed under a Creative Commons Attribution 4.0 International License. Read Full License 


\section{Abstract}

Background: Ovarian cancer is one of the deadliest and most common gynecological malignancies. This study aims to use comprehensive bioinformatics analysis to try to identify the core candidate genes related to the prediction of ovarian cancer for the early diagnosis and prognosis of ovarian cancer.

Methods: Obtain expression profiles from Gene Expression Omnibus database, identify differentially expressed genes (DEG) with $p<0.05$ and (logFC) $>1.5$, perform functional enrichment, protein-protein interaction (PPI) network construction, functional module analysis, and survival analysis And correlation analysis to obtain the target gene, through immunohistochemical staining, clinicopathological feature analysis to verify the expression and clinical significance of TTK.

Results: 1. Identified 135 genes with the same expression. 33 up-regulated DEG were mainly enriched in mitotic spindle assembly checkpoints, chromosome segregation regulation, etc.; 102 down-regulated DEG was mainly enriched in neurotransmitter level regulation, protein serine/threonine Regulation of acid kinase activity, etc. Then the PPI network was constructed to screen 20 hub genes and perform survival analysis and expression correlation analysis. At the same time, the modules that met the requirements were screened and the genes were analyzed by pathway enrichment. It was found that TTK was highly expressed in ovarian cancer and led to a poor prognosis.2. Distant metastasis, lymph node metastasis, clinical staging (stage III-IV), and poor differentiation are independent risk factors for high TTK expression $(P<0.05) .3$. TTK, CA125, HE4 three biological indicators show excellent diagnostic value in joint monitoring of ovarian cancer.

Conclusions: TTK plays a vital role in the tumorigenesis, aggressiveness and malignant biological behavior of EOC, and can be used as a potential biomarker and potential therapeutic target for early diagnosis and predictive evaluation of EOC.

\section{Introduction}

Ovarian cancer is one of the most common gynecological malignancies in the female reproductive system worldwide, with the characteristics of high metastasis, chemotherapy resistance, and postoperative recurrence $(1,2)$. The 5 -year survival rate of early $(I, \varangle)$ ovarian cancer is about $90 \%$, while only $20-40 \%$ of patients with advanced (III, 区) ovarian cancer have a survival time of more than 5 years $(3,4)$. More than $70 \%$ of patients are at an advanced stage at the time of diagnosis, and the morbidity and mortality of OC patients have increased significantly in recent years. Despite advances in treatment, the 5-year survival rate of OC patients is still less than $40 \% \nabla 5 \rrbracket$. Epithelial ovarian cancer (EOC) has the highest mortality rate among gynecological malignancies, and it is still the deadliest type that threatens

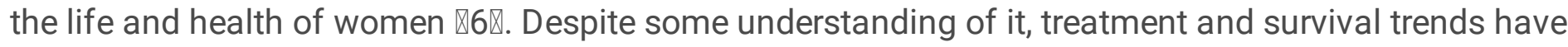
not changed significantly because early diagnosis remains a challenge. This is partly due to several factors; lack of clear screening tools, vague signs and symptoms may be "disguised" as other nonmalignant diseases (7). 
Given the lack of specific diagnostic and prognostic molecular markers for EOC, many studies have confirmed the effectiveness of serum human epididymis secretory protein 4 (HE4) in the preoperative diagnosis of patients with ovarian tumors. Verify its specificity. The sensitivity of HE4 and carbohydrate antigen 125 (CA125) overlapped (79\%)and HE4 showed a significantly higher specificity than CA125 (93\% vs. $78 \%$ ). They also confirmed that HE4 is superior to CA125 in the diagnosis of ovarian cancer. Although HE4 has higher sensitivity and specificity than CA125 in the diagnosis stage, the combination of the two markers seems to be beneficial (8). Nevertheless, a single indicator used to evaluate EOC is greatly affected by individual differences, so finding new indicators and combining them with existing indicators to predict the development and outcome of EOC has important clinical significance. Besides, gene dysregulation has been shown to play a key role in the occurrence of EOC (7). In the era of targeted therapy, mutation analysis of cancer is a key aspect of making treatment decisions. Therefore, looking for a sensitive and specific biomarker for early diagnosis and predictive evaluation of EOC, and becoming a target for ovarian cancer treatment Vital. Currently, bioinformatics analysis methods are often used in research to identify potential biomarkers that affect disease development.

In this study, we downloaded four original microarray data sets (GSE54388, GSE27651, GSE18520, and GSE26712) from the NCBI Gene Expression Comprehensive Database, with a total of 329 samples, including 297 epithelial ovarian cancer samples and 32 normal ovarian samples, Use R software to identify differentially expressed genes (DEG) between epithelial ovarian cancer and normal controls, and perform functional enrichment analysis. Also, a PPI network of 135 DEGs and key modules was established, and module analysis, survival analysis, and correlation analysis were performed. Through literature review, the important gene TTK related to epithelial ovarian cancer prediction was finally obtained.

Threonine and tyrosine kinase (TTK) is a dual-specific protein kinase that can phosphorylate threonine/serine and tyrosine (9). It is the core component and main regulator of the spindle assembly checkpoint (SAC), which can recruit and coordinate other SAC protein kinases to the kinetochore, thereby ensuring faithful chromosome separation and maintaining genome stability $(10,11)$. Elevated levels of TTK are easily found in many types of human tumors, such as glioblastoma, thyroid cancer, breast cancer, hepatocellular carcinoma, pancreatic cancer, and prostate cancer (12-18). This differential expression is suggested that can be used as a molecular biomarker for clinical diagnosis. We reviewed relevant clinical studies and trials on TTK in several human cancers (19), however, no experimental studies on TTK expression in EOC patients were found. In this study, we used immunohistochemistry to detect the expression of TTK in ovarian epithelial tumor specimens and analyzed the relationship between TTK expression and clinicopathological parameters of EOC patients.

\section{Conclusion}

gene expression profile data.This study included four GEO data sets, including a total of 297 ovarian cancer samples and 32 healthy control samples (Table 2). They were standardized by the limma software package in the R/Bioconductor software (Fig. 1). 812, 2820, 1495 and 536 DEGs were screened out 
respectively $(P<0.05,|\log F C|>1.5)$. The differentially expressed genes in the sample data of the 4 data sets are shown in Fig. 2 (Fig. 2). Use VennDiagram package to perform gene integration of DEG that meets the standard. In conclusion, compared with normal OV tissue, a total of 135 (33 up-regulated genes and 102 down-regulated genes) in OC tissue samples were identified as DEG (Table 3).

enrichment analysis.The cluster profiler package was used in R software to biologically annotate 33 upregulated DEGs and 102 down-regulated DEGs after integration, and the $G O$ function enrichment with Pvalue $<0.05$ was obtained. The significant results of $\mathrm{GO}$ enrichment analysis showed that: 1 . In the cell composition, the up-regulated DEG is mainly enriched in the double-strain tight junction, late promotion complex, apical junction complex, tight junction, and nuclear ubiquitin junction complex. Down-regulated DEG is mainly enriched in the extracellular matrix, collagen-containing extracellular matrix, and blood particles; 2. In biological processes, up-regulated DEG is enriched in mitotic spindle assembly checkpoints, chromosome separation and regulation, and cell cycle The regulation of later transitions, the positive regulation of ubiquitin-protein ligase activity, the involvement of signal transduction in gene expression regulation and chromosome separation, etc. The down-regulated DEG is obviously enriched in the regulation of neurotransmitter levels, the regulation of blood coagulation, protein serine/thereon The regulation of amino acid kinase activity, the process of mucopolysaccharide metabolism, and the Wnt signaling pathway; 3 . In the molecular function group, the down-regulated DEG is mainly enriched in heparin-binding and frizzled binding, while the up-regulated DEG is not significantly enriched in compliance with the standard. (Table 4 \& Fig. 3)

PPI network and module analysis.The STRING database was used to establish a PPI network, and 152 protein pairs were obtained. The PPI network was constructed after the comprehensive score $>0.4$ and the removal of 29 individual nodes (Fig. 4). The gene data was input into Cytoscape software, and a PPI network diagram containing 29 up-regulated DEG and 77 down-regulated DEG was further obtained. MCODE detected a total of 4 modules, and we chose the module with a higher score for the next analysis (Fig. 5). Use the MCC algorithm in Cytohubba to get the top 20 hub genes, which are: KDR, SOX9, EPCAM, WNT5A, FGF13, PDGFRA, CP, ALDH1A1, KLF4, CDC20, UBE2C, FGF9, SOX17, TTK, TRIP13, CKS2, RACGAP1, CD24, CHGB, LAMB1.

gene enrichment through KEGG pathway.In order to understand the functions of the modules, we have performed KEGG enrichment analysis for each module. The results are shown in(Table 5). TRIP13, RACGAP1, CKS2, UBE2C, TTK, and CDC20 in module 1 all up-regulate DEG, which is mainly enriched in the cell cycle and ubiquitin-mediated proteolysis pathways. There are four genes ALDH1A1, CD24, EPCAM, and SOX9 in module 2. Except for ALDH1A1 which is down-regulated DEG, the other 3 genes are all up-regulated DEG. There is no obvious pathway enrichment in this module. There are four genes $C P$, LAMB1, CHRDL1, and CHGB in module 3. Except for CP which up-regulates DEG, the rest are downregulated DEG. After enrichment, CP exists in iron death, porphyrin, and chlorophyll metabolism pathways, and LAMB1 is in ECM receptor Interaction, small cell lung cancer, and other pathways exist. 
survival analysis and expression level analysis of hub gene.We used the Kaplan Meier Plotter online website to analyze the survival of 20 hub genes and found that 13 genes associated with ovarian cancer have a poor prognosis $(P<0.05$, Fig. 6$)$. Then use the GEPIA online database to mine the expression levels of 13 genes between ovarian cancer patients and normal people. The results showed that compared with normal ovarian samples, among the 13 prognostic-related genes in ovarian cancer samples, SOX9, EPCAM, CP, UBE2C, TTK, RACGAP1, and CD24 7 genes reflected high expression $(P<0.01$, Fig. 7 ).

clinicopathological characteristics and TTK expression.In this study, the average age of all patients at surgery was 52 years, and the median age was 53 years. Among them, $59.1 \%$ of patients with epithelial ovarian cancer have lymph node metastasis. The proportion of middle-high-middle-differentiated cancer was $43.0 \%$. $56.9 \%$ of patients had distant metastases. We found that the expression of TTK was negative in normal ovarian tissues. In tumor tissues, all specimens had positive cytoplasmic staining, and the expression of a benign group, borderline group, and malignant group increased in turn. We calculated the $\mathrm{H}$ score of TTK expression in tumor tissues. Among them, the $\mathrm{H}$ score is 180 (10-220).(Table 6\&Figure 8)

analysis of the correlation between TTK expression and clinicopathological factors. We found that there was no significant correlation between TTK expression and age and fertility level. However, there is a significant positive correlation between TTK expression and tumor differentiation, CA125 level, HE4 level, clinical stage, lymphatic metastasis, and distant metastasis. Compared with patients with normal CA125, HE4, moderately well-differentiated, stage I-II, no lymph node metastasis, and no distant metastasis, CA125 elevated, HE4 elevated, poorly differentiated, stage III-IV, lymph node metastasis, and distant metastasis patients, TTK expression rate is higher, multivariate logistic regression analysis with statistically significant clinical-pathological factors in the univariate analysis as independent variables, the results show: distant metastasis, lymph node metastasis, clinical stage (III-IV), Poor differentiation is an independent risk factor for high TTK expression $(P<0.05)$. (Table 7\&Table 8)

the ROC curve analysis of TTK, CA125, and HE4 alone and combined detection for diagnosis of ovarian cancer. Draw the ROC curve with the benign ovarian tumor group as the reference, and calculate the AUC, the AUC of TTK, CA125, and HE4 in the joint monitoring of ovarian cancer are $0.927,0.899$, and 0.882 , respectively, which are significantly higher than when each index is tested separately. The three biological indicators of TTK, CA125, and HE4 show excellent diagnostic value in the joint monitoring of ovarian cancer.(Fig. 9)

\section{Discussion}

Genetic instability is a hallmark of cancer cells. This instability is caused by aneuploidy, with an abnormal genome structure and an abnormal number of chromosomes. This state is closely related to chromosome instability (CIN) (34). SAC is a key monitoring mechanism. It prevents the misdivision of chromosomes by delaying the process of mitosis until all chromosomes are correctly attached to the spindle microtubules, which can ensure the accurate separation of chromosomes. The inactivation of the spindle assembly checkpoint will lead to the premature exit of the mitotic point, which will eventually lead to chromosome 
instability, aneuploidy formation, and even cell death. SAC can ensure healthy cell growth and precise division. TTK is the core component of the spindle assembly checkpoint (SAC), and the function of SAC depends on the activity of TTK (35-37). Because TTK plays a vital role in maintaining chromosome stability, more and more researchers have begun to pay attention to the relationship between TTK expression and tumor development. Although TTK has conducted relevant basic and clinical studies in many human malignant tumors, we have not found similar studies in ovarian cancer. This study found that the expression level of TTK in tumor tissues was significantly elevated, while the expression in normal ovarian tissues was negative. It is confirmed with the existing literature that through Northern blot analysis, except for the testis and placenta, the TTK gene transcript is almost not detected in normal organs. However, high levels of TTK are easily found in many types of human malignancies, and the abnormal expression of TTK will inevitably affect the function of SAC (38). Compared with the same period last year, TTK is overexpressed in many malignant tumors, and the prognosis of patients with TTK overexpression is poor. We speculate that TTK may play a subtle role in the occurrence of ovarian cancer. It has been widely recognized that chromosomal instability is related to tumor heterogeneity, chromosomal abnormalities, and aneuploidy formation. the existence of aneuploidy can be found in the earliest stage of tumor formation, and chromosomal instability Stability is the basic process of tumorigenesis (39). At present, in gastric cancer and colorectal cancer with microsatellite instability, tumor-related TTK box shift mutations have been found, which can lead to the premature termination of TTK synthesis (40). Whether there is a similar process in ovarian cancer remains to be studied.

In addition to the difference in TTK expression in epithelial ovarian tumors and normal ovarian tissues, we further analyzed the TTK expression level in EOC patient tissues and its correlation with clinicopathological factors through the Chi-square test and found that TTK expression is related to tumor differentiation, There is a significant positive correlation between clinical stages. High TTK expression may contribute to tumor invasion, lymph node metastasis, and distant metastasis. For patients with the same clinical stage, the survival time of patients with low TTK expression is likely to be longer than that of patients with low TTK expression. The expression level of TTK can predict the development and outcome of EOC patients, and TTK can be used as a biomarker to predict the prognosis of EOC. To make some medical decisions for clinicians. For example, compared with patients with high TTK expression, ovarian cancer patients with low TTK expression are more likely to benefit from adjuvant chemotherapy. Clinically, for patients with early-stage ovarian cancer, if high TTK expression is found in these specimens, doctors and patients need to pay more attention, because these patients are potentially high-risk groups of lymphatic metastasis or distant metastasis in the future. Using a combination of conventional pathology and TTK expression may improve the survival prognosis of these patients.

It is worth mentioning that our research can provide a theoretical basis for TTK immunotherapy and targeted therapy in different tumors. TTK can be used as an ideal immune epitope antigen to induce strong peptide-specific cytotoxic T lymphocyte activity, thereby fighting tumor cells. Its safety, immunogenicity, and clinical reactivity have been confirmed in clinical trials including lung cancer, esophageal cancer, and cholangiocarcinoma (41-47). Even, TTK can be used as a new therapeutic target and become a new method for the treatment of some tumors, including glioblastoma, breast cancer, 
hepatocellular carcinoma, lung cancer, and pancreatic cancer (48-52). And in the studies of glioblastoma, breast cancer, and lung cancer (53-55), it was found that the combination of TTK inhibitors and chemotherapeutics can improve the efficacy of chemotherapeutics and reduce the adverse reactions of chemotherapeutics. From many studies, we have found that TTK inhibits The agent can not only weaken the invasion and activity of tumor cells, increase autophagy and apoptosis, but also can combine with chemotherapy drugs to enhance the efficacy. For the above-mentioned tumors, TTK overexpression is fully utilized, TTK targeted therapy or immunotherapy is feasible, and whether TTK inhibitors can become a new EOC therapeutic target is still further confirmed.

Ovarian cancer is one of the most common malignant tumors of the female reproductive system. Its early clinical features are not significant and it is highly concealed. Therefore, most patients are difficult to detect and diagnose and treat in time. When the clinical diagnosis is made, the patient is already in the middle and advanced stages. It is not ideal, so improving the diagnostic accuracy of ovarian cancer has important clinical value and significance (56). Tumor markers, or tumor markers, are substances that are characteristically present in malignant tumor cells, or are abnormally expressed and secreted by them, or are abnormal substances produced by tumor cells to stimulate host-related cells, which reflect the occurrence and development of malignant tumors. A class of abnormal substances is used to evaluate the treatment and prognosis of malignant tumors. Tumor markers can exist in tumor tissues, blood, milk, bile, and other body fluids and excrements such as urine and feces of tumor patients (57). Therefore, the detection of relevant tumor markers by immunological, biological, or chemical methods can not only assess The severity of the disease and the prognostic outcome of treatment for patients with malignant tumors, and the detection of relevant representative markers for suspected patients also helps to improve the accuracy of existing examination techniques for the diagnosis of malignant tumors (58).

So far, effective methods for early detection of ovarian cancer are still lacking. In order to improve the prognosis and improve the quality of life of patients, the early diagnosis of ovarian cancer has always attracted people's attention. The traditional tumor marker CA125 is widely used in the diagnosis, treatment, and monitoring of ovarian cancer. High sensitivity, but easily affected by physiological factors such as menstruation. In comparison, HE4 has strong specificity in the diagnosis of ovarian cancer, but it also has certain limitations. Therefore, the joint measurement of multiple indicators

\section{Materials And Methods}

gene expression profiling data.GENE EXPRESSION OMNIBUS (GEO) is a public repository created by the National Center for Biotechnology Information (NCBI) to store various forms of high-throughput genomics data (14). Gene expression profile data (GSE54388, GSE27651, GSE18520, GSE26712) are all from the Gene Expression Database (GEO). The above data sets all contain gene expression profiles and contain at least 20 cancer and healthy control samples, which have also been used to publish related literature(1519). 
comprehensive analysis of microarray data set.Based on the programming language $\mathrm{R}$, there are hundreds of software packages in Bioconductor for high-throughput sequencing in analytical genomics (20). Use hgu133plus2.db annotation package (version 3.2.3) and hgu133a.DB annotation package (version 3.2.3) to convert probe ID to gene name. The limma software package (version 3.40.2) (21) was used to normalize and log 2 conversions of the data in the data set, and the DEG of the ovarian cancer tissues in the 4 data sets compared with the control was identified through a linear model. $|\log F C|>1.5$ and $\mathrm{P}<0.05$ were considered statistically significant for $\mathrm{DEG}$. $|\log \mathrm{FC}|>1.5$ is considered to increase $\mathrm{DEG}$, $|\log F C|<1.5$ is considered to decrease DEG. The Venn-diagram software package (version 1.6.20) (22) is used to integrate the genes that meet the criteria in the four data sets and visualize them with a Venn diagram.

functional and pathway enrichment analysis.The Clusterprofiler package (version 3.10.2) was used to perform function and pathway enrichment analysis on DEGs to explore the biological significance, and the significance threshold was set at $\mathrm{P}<0.05$. Gene ontology (GO) function enrichment mainly describes the functions of genes and gene products in all organisms from three aspects: cell components (CC), biological processes (BP), and molecular functions (MF) (23). The Kyoto Encyclopedia of Genes and Genomes (KEGG) pathway enrichment analysis explains genes from their biochemical pathways and regulatory pathways (24).

PPI network construction and module screening.To evaluate the functional interaction of DEG, use the gene database STRING to search for protein interactions to map DEGS to the PPI network to generate a combined score, and the cut-off value is a comprehensive score $\geq$ of 0.4 . Cytoscape software (version 3.7.2) (25) was used to construct a PPI network for visualization and biological analysis to identify the interaction between DEG-encoded proteins in ovarian cancer. To improve sensitivity and specificity, we used Cytoscape plug-in Cytohubba's MCC algorithm (26) to perform the next biological analysis on 20 hub genes. At the same time, the Cytoscape plug-in Molecular Complex Detection (MCODE) is used to detect dense areas of the PPI network (Degree Cutoff $=2$, Node Score Cutoff $=0.2$, and K-Core $=2$, maximum depth $=100$ is set as an advanced option) (27), Select the module that meets both the MCODE score $>3$ and the number of nodes $>4$ and performs KEGG enrichment analysis on DEGs.

survival analysis of central genes.Kaplan-Meier Plotter is an online database containing a large number of gene expression data and clinical data of patients with ovarian cancer (28). We use this library to analyze the selected 20 hub genes to evaluate their prognostic value. The graph can directly display the log-rank P-value and the hazard ratio (HR) of the $95 \%$ confidence interval, and select genes with a log-rank $P$-value of $<0.05$.

analysis of hub gene expression level .In order to verify the expression of the hub gene in ovarian cancer, use GEPIA (gene expression profile interactive analysis) (29) to match the normal data of TCGA (tumor genome atlas) and GTEX (genotype tissue expression) to the selected hub genes that affect the prognosis, Setting $\mathrm{P}<0.01$ has significant statistical significance, and the level of gene expression is displayed in the form of box plots. 
patient and paraffin-embedded tissue samples.This study was approved by the Ethics Committee of the Affiliated People's Hospital of Shanxi Medical University. From 2015 to 2020, the Department of Obstetrics and Gynecology, Affiliated People's Hospital of Shanxi Medical University collected 150 patients and postoperative paraffin-embedded specimens. The pathological diagnosis of all tissue sections was confirmed by internal experts, as follows: malignant group $n=93$, borderline group $n=27$, benign group $n=15$, normal group $n=15$. The pathological types of ovarian cancer are 65 cases of serous adenocarcinoma, 13 cases of mucinous adenocarcinoma, 10 cases of endometrioid carcinoma, and 5 cases of clear cell carcinoma. In the malignant group, there were 40 cases, 53 cases of welldifferentiated and poorly differentiated. According to the standards of the International Federation of Obstetrics and Gynecology (FIGO, 2009), the pathological stage is judged as follows: FIGO I-II stage (36 cases) and FIGO III-IV stage (57 cases). Lymph node metastasis was judged as follows: no metastasis (48 cases), metastasis (55 cases). All patients were primary ovarian cancer, with complete clinical and pathological data. Patients who received chemotherapy, radiotherapy, and hormone therapy before surgery were not implemented in this study.(Table 1)

TTK immunohistochemistry and H score. All fresh tissue specimens were collected immediately after surgical resection and immersed in $10 \%$ neutral buffered formalin solution, and then embedded in paraffin. The paraffin-embedded tissue sections were 5 meters in thickness and stained by immunohistochemistry. Immunohistochemical staining is performed manually, and each slide is processed strictly in accordance with the immunohistochemistry protocol. TTK polyclonal antibody (ab219068, Abcam, UK, 1:100). Paraffin-embedded tissue sections were deparaffinized with xylene and gradient alcohol, washed with PBS, hot antigen retrieval, $3 \%$ hydrogen peroxide to block endogenous peroxides, and incubated with rabbit TTK antibody $(1: 500)$ at $4^{\circ} \mathrm{C}$ overnight. The reaction enhancement solution was added dropwise for 30 minutes, and then the enzyme-labeled anti-rabbit secondary antibody reagent was incubated for 30 minutes. Diaminobenzidine was used for color development, hematoxylin counterstaining, dehydration, and neutral resin mounting. The manufacturer recommends testicular tissue as a positive control. The immunohistochemical sections were independently evaluated blindly by two experienced pathologists. TTK staining is evaluated using the $\mathrm{H}$ scoring system, which is calculated by multiplying the total staining intensity by the percentage of positive cells $(30-33)$. The staining intensity was graded from 0 to 3 ( 0 =negative, $1=$ weak, $2=$ medium, $3=$ strong), and the percentage of positives increased from 0 to 100 . In theory, the final high score is obtained in the range of 0 to 300 .

\section{Statistical analysis}

Analyze the data with SPSS 26.0 statistical software, and perform a single factor chi-square test for the clinicopathological factors of epithelial ovarian cancer, the test level is $a=0.05$; the combined predictor can be obtained by logistic regression model analysis, and the predictive evaluation value of the research factors can be passed Receiver operating characteristic curve (ROC curve) for analysis, $a=0.05$.

\section{Declarations}




\section{Thanks}

Not applicable

\section{Acknowledgements}

Not applicable.

\section{Funding}

No funding was received

\section{Availability of data and materials}

The datasets analyzed during the current study are available in the GEO repository, https://www.ncbi.nlm.nih.gov/geo/query/acc.cgi?acc=GSE54388》 https://www.ncbi.nlm.nih.gov/geo/query/acc.cgi?acc=GSE27651区 https://www.ncbi.nlm.nih.gov/geo/query/acc.cgi?acc=GSE18520区 https://www.ncbi.nlm.nih.gov/geo/query/acc.cgi?acc=GSE26712.

\section{Authors' contributions}

QF designed the study. JB, QQ and HM analyzed and interpreted the microarray datasets, and produced the manuscript. JB wrote the paper and submitted the manuscript. JB and MM performed the experiments. All authors read and approved the final manuscript.

\section{Ethics approval and consent to participate}

This study has been approved by research ethics Shanxi Provincial People's Hospital Committee. Written notice Agree to conduct analysis of tissue specimens in this study

Obtained from the patient.

\section{Patient consent for publication}

Not applicable.

\section{Competing interests}

The authors declare that they have no competing interests.

\section{References}

1. Silvia T, Michele-Antonio C, Stefano M, Giorgio A, Palma M and Antonio R囚Gynecological cancer among adolescents and young adults (AYA)『Ann Transl Med 8囚397, 2020区 
2. Moufarrij S, Dandapani A, Arthofer E, Gomez S, Srivastava A, Lopez-Acevedo M, Villagra A and Chiappinelli KB囚Epigenetic therapy for ovarian cancer $\$ promise and progress $₫$ Clin Epigenet $11 \otimes 7$, 2019区

3. Zeppernick F and Meinhold-Heerlein IQThe new FIGO staging system for ovarian, fallopian tube, and primary peritoneal cancer\Arch Gynecol Obstet 290冈839-842, 2014】

4. Schiavone MB, Herzog TJ, Lewin SN, Deutsch I, Sun XM, Burke WM and Wright JD『Natural history

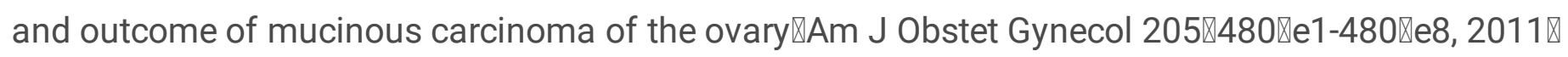

5. Charkhchi P, Cybulski C, Gronwald J, Wong FO, Narod SA and Akbari MR囚CA125 and ovarian cancer》 a comprehensive review $₫$ Cancers 12₫3730, 2020》

6. Gong M, Yan CS, Jiang Y, Meng HY, Feng MM and Cheng WJ $\triangle$ Genome-wide bioinformatics analysis reveals CTCFL is upregulated in high-grade epithelial ovarian cancer $₫$ Oncol Lett 18 $\$ 4030-4039,2019 \rrbracket$

7. Stewart C, Ralyea C and Lockwood $S \bowtie O v a r i a n$ cancer $\rrbracket A n$ integrated review $₫$ Semin Oncol Nurs $35 \rrbracket$ 151-156, 2019凶

8. Potenza E, Parpinel G, Laudani ME, Macchi C, Fuso L and Zola P凶Prognostic and predictive value of combined HE4 and CA125 biomarkers during chemotherapy in patients with epithelial ovarian cancer冈Int J Biol Markers 35 $202-27,2020 \rrbracket$

9. Fisk HA, Mattison CP and Winey M $₫ A$ field guide to the Mps 1 family of protein kinases $\llbracket C e l l$ Cycle $3 \rrbracket$ 439-442, 2004】

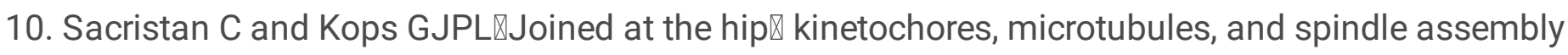
checkpoint signaling $₫$ Trends Cell Biol 25『21-28, 2015》

11. Santaguida $S$ and Amon $\varangle$ Short- and long-term effects of chromosome mis-segregation and

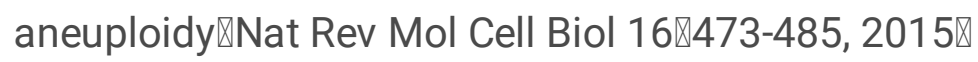

12. Stratford JK, Yan F, Hill RA, Major MB, Graves LM, Der CJ and Yeh JJ『Genetic and pharmacological inhibition of TTK impairs pancreatic cancer cell line growth by inducing lethal chromosomal instability $\otimes P L o S$ One 12》e0174863-e0174863, 2017》

13. Riggs JR, Nagy M, Elsner J, Erdman P, Cashion D, Robinson D, Harris R, Huang D, Tehrani L, DeyanatYazdi G, at a冈The discovery of a dual TTK protein kinase/CDC2-like kinase (CLK2) inhibitor for the treatment of triple negative breast cancer initiated from a phenotypic screen $₫ \mathrm{~J}$ Med Chem 60ख89899002, 2017区

14. King JL, Zhang B, Li Y, Li KP, Ni JJ, Saavedra HI and Dong JTQTTK promotes mesenchymal signaling

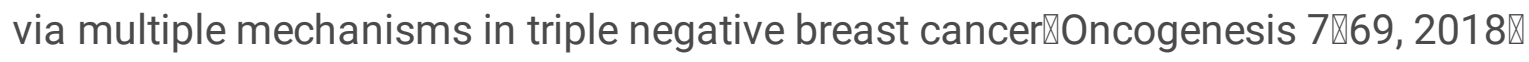

15. Yeung TL, Leung CS, Wong KK, Gutierrez-Hartmann A, Kwong J, Gershenson DM, and Mok SC区ELF3 is a negative regulator of epithelial-mesenchymal transition in ovarian cancer cells.Oncotarget $8 \triangle$ 14951-14963, 2017.

16. King ER, Tung CS, Tsang YT, Zu Z, Lok GT, Deavers MT, Malpica A, Wolf JK, Lu KH, Birrer MJ, at al The anterior gradient homolog 3 (AGR3) gene is associated with differentiation and survival in ovarian cancer.Am J Surg Pathol 35ष904-912, 2011区 
17. Mok SC, Bonome T, Vathipadiekal V, Bell A, Johnson ME, Wong KK, Park DC, Hao K, Yip DK, Donninger $\mathrm{H}$, at a/ $\mathbb{A}$ gene signature predictive for outcome in advanced ovarian cancer identifies a survival factor: microfibril-associated glycoprotein 2『Cancer Cell 16囚521-532, 2009.

18. Bonome T, Levine DA, Shih J, Randonovich M, Pise-Masison CA, Bogomolniy F, Ozbun L, Brady J, Barrett JC, Boyd J, at a®A gene signature predicting for survival in suboptimally debulked patients with ovarian cancer》Cancer Res 68ه5478-5486, 2008》

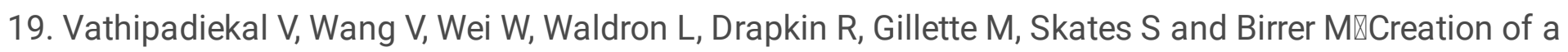
Human Secretome: A Novel Composite Library of Human Secreted Proteins: Validation Using Ovarian Cancer Gene Expression Data and a Virtual Secretome Array.Clin Cancer Res 21ه4960-4960, 2015区

20. Chen X, Yu C, Gao J, Zhu H, Cui B, Zhang T, Zhou Y, Liu Q, He H, Xiao R, at a/ A novel USP9X substrate TTK contributes to tumorigenesis in non-small-cell lung cancer冈Theranostics 8ه2348-2360, 2018区

21. Miao R, Wu Y, Zhang H, Zhou H, Sun X, Csizmadia E, He L, Zhao Y, Jiang C, Miksad RA, at a/XUtility of the dual-specificity protein kinase TTK as a therapeutic target for intrahepatic spread of liver cancer $\bigotimes$ Sci Rep 6囚33121, 2016》

22. Tannous BA, Kerami M, Van der Stoop PM, Kwiatkowski N, Wang J, Zhou W, Kessler AF, Lewandrowski G, Hiddingh L, Sol N, at al『Effects of the selective MPS1 inhibitor MPS1-IN-3 on glioblastoma sensitivity to antimitotic drugs $₫ \mathrm{~J}$ Natl Cancer Inst 105 $\ 1322-1331,2013 \rrbracket$

23. Ling Y, Zhang X, Bai Y, Li P, Wei C, Song T, Zheng Z, Guan K, Zhang Y, Zhang B, at a凡 Overexpression of Mps 1 in colon cancer cells attenuates the spindle assembly checkpoint and increases aneuploidy $\mathbb{Z}$ Biochem Biophys Res Commun 450囚1690-1695, 2014囚

24. Xie Y, Lin JZ, Wang AQ, Xu WY, Long JY, Luo YF, Shi J, Liang ZY, Sang XT and Zhao HT囚Threonine and tyrosine kinase may serve as a prognostic biomarker for gallbladder cancer $\otimes$ World $\mathrm{J}$ Gastroenterol 23₫5787-5797, 2017》

25. Barrett T, Wilhite SE, Ledoux P, Evangelista C, Kim IF, Tomashevsky M, Marshall KA, Phillippy KH,

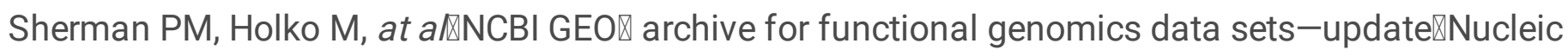
Acids Research 41هD991-D995, 2013凶

26. Huber W, Carey VJ, Gentleman R, Anders S, Carlson M, Carvalho BS, Bravo HC, Davis S, Gatto L, Girke $\mathrm{T}$, at $a \mathbb{\bigotimes}$ Orchestrating high-throughput genomic analysis with Bioconductor $₫$ Nat Methods $12 \rrbracket 115-121$, 2015区

27. Ritchie ME, Phipson B, Wu D, Hu YF, Law CW, Shi W and Smyth GKXLimma powers differential expression analyses for RNA-sequencing and microarray studies $₫$ Nucleic Acids Res 43囚e47, 2015】

28. Chen HB and Boutros $P C \otimes V e n n D i a g r a m \rrbracket$ a package for the generation of highly-customizable venn and euler diagrams in R囚BMC Bioinformatics 12 $\varangle 35,2011 \rrbracket$

29. Thomas PDQThe gene ontology and the meaning of biological function $₫$ Methods Mol Biol 1446ه1524, 2017》

30. Ogata H, Goto S, Sato K, Fujibuchi W, Bono H and Kanehisa M $\triangle$ KEGG $₫$ kyoto encyclopedia of genes and genomes $₫$ Nucleic Acids Res 27区29-34, 1999『 


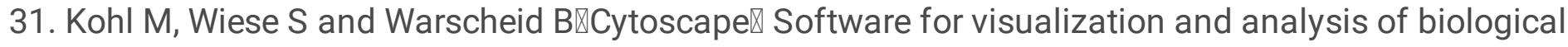
networks $₫$ Methods Mol Biol 696ه291-303, 2011》

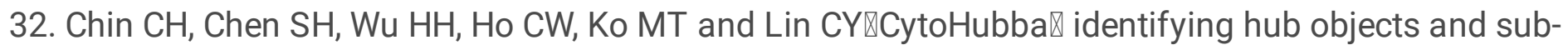

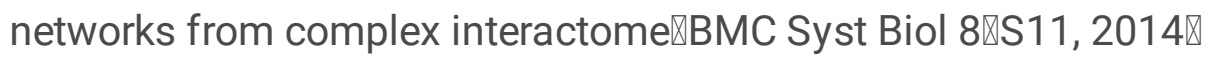

33. Bader GD and Hogue CWV $\triangle A n$ automated method for finding molecular complexes in large protein interaction networks $\varangle \mathrm{BMC}$ Bioinformatics 4『2, 2003『

34. Gyorffy B, Lánczky A and Szállási Z囚lmplementing an online tool for genome-wide validation of survival-associated biomarkers in ovarian-cancer using microarray data from 1287 patients $\varangle$ Endocr Relat Cancer 19囚197-208, 2012》

35. Tang ZF, Li CW, Kang BX, Gao G, Li C and Zhang ZM®GEPIA $\triangle$ a web server for cancer and normal gene expression profiling and interactive analyses $₫$ Nucleic Acids Res 45『W98-W102, 2017》

36. Yeo W, Chan SL, Mo FKF, Chu CM, Hui JWY, Tong JHM, Chan AWH, Koh J, Hui EP, Loong H, at al Phase I/II study of temsirolimus for patients with unresectable hepatocellular carcinoma (HCC)- a correlative study to explore potential biomarkers for response『BMC Cancer 15囚395, 2015》

37. Specht E, Kaemmerer D, Sänger J, Wirtz RM, Schulz S and Lupp A囚Comparison of immunoreactive score, HER2/neu score and $\mathrm{H}$ score for the immunohistochemical evaluation of somatostatin receptors in bronchopulmonary neuroendocrine neoplasms $\triangle H i s t o p a t h o l o g y ~ 67 \rrbracket 368-377,2015 \rrbracket$

38. Liang PI, Li CF, Chen LT, Sun DP, Chen TJ, Hsing CH, Hsu HP and Lin CY®BCL6 overexpression is associated with decreased p19 ARF expression and confers an independent prognosticator in gallbladder carcinoma $₫ T$ Tumour Biol 35凶1417-1426, 2014区

39. Budwit-Novotny DA, McCarty KS, Cox EB, Soper JT, Mutch DG, Creasman WT, Flowers JL and McCarty KS囚Immunohistochemical analyses of estrogen receptor in endometrial adenocarcinoma using a monoclonal antibody $₫$ Cancer Res 46ه5419-5425, 1986ه

40. Kusakabe K, Ide N, Daigo Y, Itoh T, Yamamoto T, Hashizume H, Nozu K, Yoshida H, Tadano G,

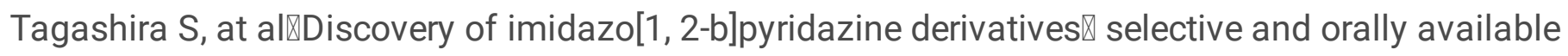

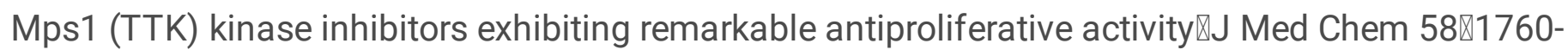
$1775,2015 \square$

41. Lauzé E, Stoelcker B, Luca FC, Weiss E, Schutz AR and Winey M $\otimes$ Yeast spindle pole body duplication gene MPS1 encodes an essential dual specificity protein kinase区EMBO J 14ه1655-1663, 1995区

42. Lara-Gonzalez P, Westhorpe FG and Taylor SS $₫$ The spindle assembly checkpoint $₫$ Curr Biol 22هR966R980, 2012】

43. Musacchio A囚Spindle assembly checkpoint $₫$ the third decade $\varangle$ Philos Trans R Soc Lond B Biol Sci 366ه3595-3604, 2011区

44. Danielsen HE, Pradhan M and Novelli M®Revisiting tumour aneuploidy the place of ploidy assessment in the molecular era $₫$ Nat Rev Clin Oncol 13『291-304, 2016】

45. Ahn $\mathrm{CH}$, Kim YR, Kim SS, Yoo NJ and Lee SH®Mutational analysis of TTK gene in gastric and colorectal cancers with microsatellite instability खCancer Res Treat 41ष224-228, 2009『 
46. Suda T, Tsunoda T, Daigo $\mathrm{Y}$, Nakamura $\mathrm{Y}$ and Tahara H囚Identification of human leukocyte antigenA24-restricted epitope peptides derived from gene products upregulated in lung and esophageal

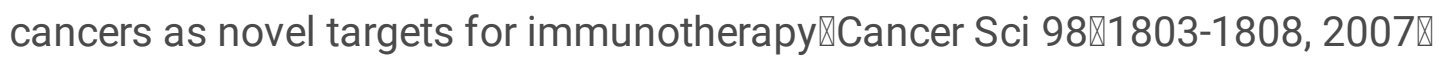

47. Suzuki H, Fukuhara M, Yamaura T, Mutoh S, Okabe N, Yaginuma H, Hasegawa T, Yonechi A, Osugi J, Hoshino M, at a/\Multiple therapeutic peptide vaccines consisting of combined novel cancer testis antigens and anti-angiogenic peptides for patients with non-small cell lung cancer囚J Transl Med 11区 97, 2013》

48. Mizukami Y, Kono K, Daigo Y, Takano A, Tsunoda T, Kawaguchi Y, Nakamura Y and Fujii H囚Detection of novel cancer-testis antigen-specific T-cell responses in TIL, regional lymph nodes, and PBL in patients with esophageal squamous cell carcinoma Cancer Sci 99 $1448-1454,2008 \rrbracket$

49. Kono K, Mizukami Y, Daigo Y, Takano A, Masuda K, Yoshida K, Tsunoda T, Kawaguchi Y, Nakamura Y and Fujii $H \otimes V$ accination with multiple peptides derived from novel cancer-testis antigens can induce specific T-cell responses and clinical responses in advanced esophageal cancer》Cancer Sci 100》 1502-1509, 2009ه

50. Kono K, linuma H, Akutsu Y, Tanaka H, Hayashi N, Uchikado Y, Noguchi T, Fujii H, Okinaka K,

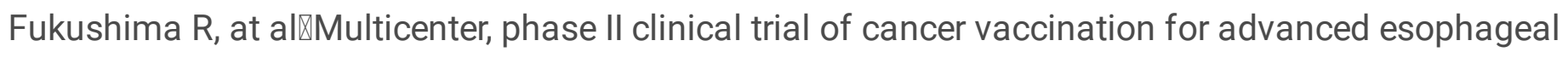

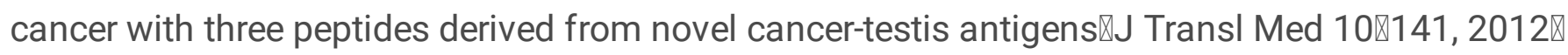

51. linuma H, Fukushima R, Inaba T, Tamura J, Inoue T, Ogawa E, Horikawa M, Ikeda Y, Matsutani N, Takeda K, at a囚Phase I clinical study of multiple epitope peptide vaccine combined with chemoradiation therapy in esophageal cancer patients $₫ J$ Transl Med 12 $884,2014 \rrbracket$

52. Aruga A, Takeshita N, Kotera Y, Okuyama R, Matsushita N, Ohta T, Takeda K and Yamamoto MखLongterm vaccination with multiple peptides derived from cancer-testis antigens can maintain a specific $\mathrm{T}$ -

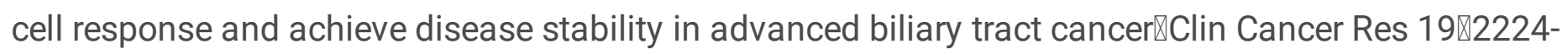
2231, 2013】

53. Tannous BA, Kerami M, Van der Stoop PM, Kwiatkowski N, Wang J, Zhou W, Kessler AF, Lewandrowski G, Hiddingh L, Sol N, at a/XEffects of the selective MPS1 inhibitor MPS1-IN-3 on glioblastoma sensitivity to antimitotic drugs $₫ \mathrm{~J}$ Natl Cancer Inst 105囚1322-1331, 2013》

54. Maia AR, de Man J, Boon U, Janssen A, Song JY, Omerzu M, Sterrenburg JG, Prinsen MB, WillemsenSeegers N, de Roos JA, at a/Inhibition of the spindle assembly checkpoint kinase TTK enhances the efficacy of docetaxel in a triple-negative breast cancer model『Ann Oncol 26ख2180-2192, 2015区

55. Wu ZX, Yang Y, Wang G, Wang JQ, Teng QX, Sun L, Lei ZN, Lin L, Chen ZS and Zou C区Dual TTK/CLK2

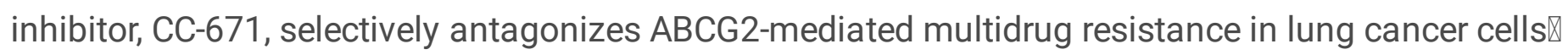
Cancer Sci 111ه2872-2882, 2020区

56. Chang L, Ni J, Zhu Y, Pang B, Graham P, Zhang H and Li Y \Liquid biopsy in ovarian cancer冈 recent advances in circulating extracellular vesicle detection for early diagnosis and monitoring progression $\otimes$ Theranostics $9 \llbracket 4130-4140,2019 \rrbracket$

57. Zhang D, Jiang YX, Luo SJ, Zhou R, Jiang QX and Linghu H囚Serum CA125 levels predict outcome of interval debulking surgery after neoadjuvant chemotherapy in patients with advanced ovarian 
cancerखClin Chim Acta 484囚32-35, 2018囚

58. Bonifácio VDB囚ovarian cancer biomarkers $\rrbracket$ moving forward in early detection $\llbracket A d v$ Exp Med Biol $1 \rrbracket$ 255-263, 2020区

\section{Tables}

Table I Clinicopathological characteristics of the cohort 


\begin{tabular}{|c|c|}
\hline Characteristics & Cases \\
\hline \multicolumn{2}{|l|}{ Age(years) } \\
\hline$\leq 52 \rrbracket$ & 38 \\
\hline$\bigotimes 52$ & 55 \\
\hline \multicolumn{2}{|l|}{ Clinical stages } \\
\hline$|-| \mid$ & 36 \\
\hline III-IV & 57 \\
\hline \multicolumn{2}{|l|}{ Lymphatic metestasis } \\
\hline with & 48 \\
\hline without & 45 \\
\hline \multicolumn{2}{|l|}{ ascites } \\
\hline with & 55 \\
\hline without & 38 \\
\hline \multicolumn{2}{|l|}{ Histoloogical differentiation } \\
\hline Intermediately and well differentiated. & 40 \\
\hline Poorly differentiated & 53 \\
\hline \multicolumn{2}{|l|}{ Pathological type } \\
\hline Serous & 65 \\
\hline Non-serous & 28 \\
\hline \multicolumn{2}{|l|}{ Whether to give birth } \\
\hline with & 76 \\
\hline without & 17 \\
\hline \multicolumn{2}{|l|}{ Distant metastasis } \\
\hline with & 53 \\
\hline without & 40 \\
\hline \multicolumn{2}{|l|}{ CA125『0-35》 } \\
\hline Normal & 28 \\
\hline Elevated & 65 \\
\hline
\end{tabular}

Page 16/32 


\begin{tabular}{|ll|} 
HE4ヌ0-140区 & \\
\hline Normal & 30 \\
\hline Elevated & 63 \\
\hline
\end{tabular}

Table II Details for GEO ovarian cancer data

\begin{tabular}{|c|c|c|c|c|c|c|}
\hline Reference & GEO & PMID & Sample & Platform & Normal & Tumor \\
\hline $\begin{array}{l}\text { Yeung T et } \\
\text { al.[15] }\end{array}$ & GSE54388 & 28199976 & Ovary & $\begin{array}{l}\text { GPL570 } \\
\text { [HG-U133_Plus_2] } \\
\text { Affymetrix Human Genome } \\
\text { U133 Plus 2.0 Array }\end{array}$ & 6 & 16 \\
\hline $\begin{array}{l}\text { Wong } \\
\mathrm{K}[16]\end{array}$ & GSE27651 & 21451362 & Ovary & $\begin{array}{l}\text { GPL570 } \\
\text { [HG-U133_Plus_2] } \\
\text { Affymetrix Human Genome } \\
\text { U133 Plus 2.0 Array }\end{array}$ & 6 & 43 \\
\hline $\begin{array}{l}\text { Birrer } \\
\text { MJ[17] }\end{array}$ & GSE18520 & 19962670 & Ovary & $\begin{array}{l}\text { GPL570 } \\
\text { [HG-U133_Plus_2] } \\
\text { Affymetrix Human Genome } \\
\text { U133 Plus 2.0 Array }\end{array}$ & 10 & 53 \\
\hline $\begin{array}{l}\text { Birrer } \\
\text { MJ[18-19] }\end{array}$ & GSE26712 & $\begin{array}{c}18593951 \\
25944803\end{array}$ & Ovary & $\begin{array}{l}\text { GPL96 } \\
\text { [HG-U133A] Affymetrix } \\
\text { Human Genome U133A } \\
\text { Array }\end{array}$ & 10 & 185 \\
\hline
\end{tabular}

Table III ALL 105 commonly DEGs were detected from four profile datasets,including 33 up-regulated genes and 102 down-regulated genes in the ovarian cancer tissues compared to normal ovary tissues. 


\begin{tabular}{|c|c|}
\hline DEGS & Genes Name \\
\hline 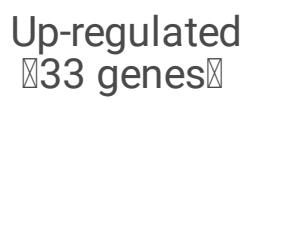 & $\begin{array}{l}\text { CRABP2 EPCAM TRIP13 CKS2 INAVA } \text { TTK MTHFD2 } \\
\text { SOX17 PFKP RACGAP1 KLK6 CLDN3 CDC20 MMP7 } \\
\text { SOX9 IDH2 CD24 UBE2C SCGB2A1 LYPD1 CP } \\
\text { HIST1H1C DEFB1 S100A2 GLDC PRAME MAL IFI27 } \\
\text { ISG15 CLDN10 LCN2 SST SCGB1D2 }\end{array}$ \\
\hline $\begin{array}{l}\text { Down-regulated } \\
\text { ه102 genes } \nabla\end{array}$ & 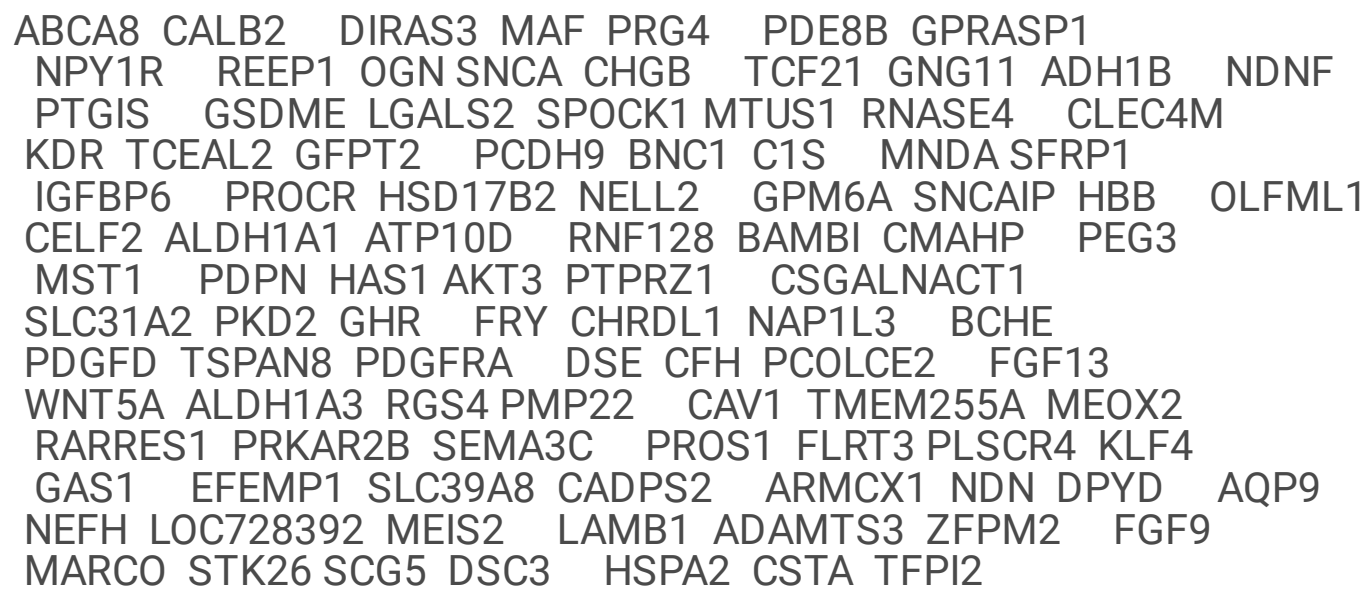 \\
\hline
\end{tabular}

Table IV Gene ontology analysis of DEGs in ovarian cancer 
Expression Category

up-
Term

GOTERM_BP_DIRECT
G0:0007094 mitotic spindle

assembly checkpoint

GOTERM_BP_DIRECT GO:0051983

GOTERM_BP_DIRECT GO:1902099

GOTERM_BP_DIRECT

GO:1904668

GOTERM_BP_DIRECT

regulation of

chromosome

segregation

regulation of

positive regulation of metaphase/anaphase

transition of cell cycle

ubiquitin protein

ligase activity

GOTERM_BP_DIRECT GO:0023019

signal transduction

involved in regulation

of gene expression

\begin{tabular}{|c|c|c|c|c|c|}
\hline & GOTERM_BP_DIRECT & GO:0007059 & $\begin{array}{l}\text { chromosome } \\
\text { segregation }\end{array}$ & 4 & $\begin{array}{l}1.393029 \mathrm{E}- \\
03\end{array}$ \\
\hline & GOTERM_CC_DIRECT & GO:0005680 & $\begin{array}{l}\text { anaphase-promoting } \\
\text { complex }\end{array}$ & 2 & $\begin{array}{l}5.851398 \mathrm{E}- \\
04\end{array}$ \\
\hline & GOTERM_CC_DIRECT & GO:0005923 & $\begin{array}{l}\text { bicellular tight } \\
\text { junction }\end{array}$ & 3 & $\begin{array}{l}1.066608 \mathrm{E}- \\
03\end{array}$ \\
\hline & GOTERM_CC_DIRECT & Go:0070160 & tight junction & 3 & $\begin{array}{l}1.202291 \mathrm{E}- \\
03\end{array}$ \\
\hline & GOTERM_CC_DIRECT & GO:0043296 & $\begin{array}{l}\text { apical junction } \\
\text { complex }\end{array}$ & 3 & $\begin{array}{l}1.537972 \mathrm{E}- \\
03\end{array}$ \\
\hline & GOTERM_CC_DIRECT & Go:0000152 & $\begin{array}{l}\text { nuclear ubiquitin } \\
\text { ligase complex }\end{array}$ & 2 & $\begin{array}{l}1.923558 \mathrm{E}- \\
03\end{array}$ \\
\hline \multirow[t]{6}{*}{$\begin{array}{l}\text { down- } \\
\text { regulated }\end{array}$} & GOTERM_BP_DIRECT & Go:0001505 & $\begin{array}{l}\text { regulation of } \\
\text { neurotransmitter } \\
\text { levels }\end{array}$ & 11 & $\begin{array}{l}1.055171 \mathrm{E}- \\
06\end{array}$ \\
\hline & GOTERM_BP_DIRECT & GO:0050818 & $\begin{array}{l}\text { regulation of } \\
\text { coagulation }\end{array}$ & 6 & $\begin{array}{l}3.860156 \mathrm{E}- \\
06\end{array}$ \\
\hline & GOTERM_BP_DIRECT & GO:0060485 & $\begin{array}{l}\text { mesenchyme } \\
\text { development }\end{array}$ & 9 & $\begin{array}{l}9.267618 \mathrm{E}- \\
06\end{array}$ \\
\hline & GOTERM_BP_DIRECT & GO:0061437 & $\begin{array}{l}\text { renal system } \\
\text { vasculature } \\
\text { development }\end{array}$ & 4 & $\begin{array}{l}1.014772 \mathrm{E}- \\
05\end{array}$ \\
\hline & GOTERM_BP_DIRECT & Go:0061440 & $\begin{array}{l}\text { kidney vasculature } \\
\text { development }\end{array}$ & 4 & $\begin{array}{l}1.014772 \mathrm{E}- \\
05\end{array}$ \\
\hline & GOTERM_BP_DIRECT & Go:0007596 & blood coagulation & 10 & $\begin{array}{l}1.019607 \mathrm{E}- \\
05\end{array}$ \\
\hline
\end{tabular}

Count P-value

$2.034627 \mathrm{E}-$

05

$2.190205 \mathrm{E}-$

05

7.461011E-

05

$2.017870 \mathrm{E}-$

04

$5.187441 \mathrm{E}-$ 04 


\begin{tabular}{lllll} 
GOTERM_CC_DIRECT & G0:0031012 & extracellular matrix & 13 & $\begin{array}{l}1.132046 \mathrm{E}- \\
06\end{array}$ \\
\hline GOTERM_CC_DIRECT & G0:0062023 & $\begin{array}{l}\text { collagen-containing } \\
\text { extracellular matrix }\end{array}$ & 10 & $\begin{array}{l}5.076567 \mathrm{E}- \\
05\end{array}$ \\
\hline GOTERM_CC_DIRECT & G0:0072562 & blood microparticle & 6 & $\begin{array}{l}1.317312 \mathrm{E}- \\
04\end{array}$ \\
\hline GOTERM_MF_DIRECT & G0:0008201 & heparin binding & 6 & $\begin{array}{l}1.440927 \mathrm{E}- \\
04\end{array}$ \\
\hline GOTERM_MF_DIRECT & G0:0005109 & frizzled binding & 3 & $\begin{array}{l}2.134040 \mathrm{E}- \\
04\end{array}$
\end{tabular}

Table V KEGG pathway analysis of genes in each module

\begin{tabular}{lllllll} 
& Pathway & ID & P-value & P-adjust & Count & Genes \\
\hline $\begin{array}{l}\text { Module } \\
\mathbf{n}\end{array}$ & Cell cycle & hsa04110 & 0.001427147 & 0.005143403 & 2 & TTK \\
\hline $\begin{array}{l}\text { Ubiquitin mediated } \\
\text { proteolysis }\end{array}$ & hsa04120 & 0.001714468 & 0.005143403 & 2 & UBE2C \\
\hline & & & & & CDC20
\end{tabular}

Module NULL

2

Module Ferroptosis

3

Porphyrin and chlorophyll metabolism

\begin{tabular}{llllll}
$\begin{array}{l}\text { ECM-receptor } \\
\text { interaction }\end{array}$ & hsa04512 & 0.022083515 & 0.042095249 & 1 & LAMB1 \\
\hline Small cell lung cancer & hsa05222 & 0.023081453 & 0.042095249 & 1 & LAMB1 \\
\hline Amoebiasis & hsa05146 & 0.025574068 & 0.042095249 & 1 & LAMB1 \\
\hline Toxoplasmosis & hsa05145 & 0.028063499 & 0.042095249 & 1 & LAMB1
\end{tabular}

Table VI TTK expression in epithelial ovarian tumors 


\begin{tabular}{|c|c|c|c|c|c|c|}
\hline \multirow[t]{2}{*}{ parameters } & \multirow[t]{2}{*}{$\mathrm{n}$} & \multicolumn{2}{|c|}{ TTK expression } & \multirow[t]{2}{*}{$\chi^{2}$} & \multirow[t]{2}{*}{$P$-value } & \\
\hline & & negative & positive & & & \\
\hline normal & 15 & $15 \bigotimes 100 \% \bigotimes$ & $0 \otimes 0 \% \rrbracket$ & & $<0.001$ & \\
\hline begign & 15 & $8 \rrbracket 53.3 \% \rrbracket$ & $7 \rrbracket 46.7 \% \rrbracket$ & 68.09 & $<0.001$ & \\
\hline Borderline & 27 & $17 \rrbracket 63.0 \% \rrbracket$ & 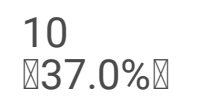 & 40.19 & $<0.001$ & \\
\hline $\begin{array}{l}\text { Malignant } \\
\text { (control) }\end{array}$ & 93 & $7 \rrbracket 7.5 \% \bigotimes$ & $\begin{array}{l}86 \\
\square 92.5 \% \rrbracket\end{array}$ & - & - & \\
\hline \multirow[t]{3}{*}{ cytoplasm } & \multicolumn{3}{|c|}{ Proportion of positive cells (\%) } & \multirow{2}{*}{\multicolumn{2}{|c|}{ Number of cases }} & \\
\hline & \multicolumn{3}{|c|}{ Median (range) } & & & \\
\hline & $\begin{array}{l}\text { malignant } \\
\text { tumor }\end{array}$ & $\begin{array}{l}\text { Borderline } \\
\text { tumor }\end{array}$ & $\begin{array}{l}\text { benign } \\
\text { tumor }\end{array}$ & $\begin{array}{l}\text { malignant } \\
\text { tumor }\end{array}$ & $\begin{array}{l}\text { Borderline } \\
\text { tumor }\end{array}$ & $\begin{array}{l}\text { benign } \\
\text { tumor }\end{array}$ \\
\hline negative & - & - & - & 7 & 17 & 8 \\
\hline positive & $90 \rrbracket 20-100 \rrbracket$ & $55 \rrbracket 10-70 \rrbracket$ & $30 \rrbracket 5-40 \rrbracket$ & 86 & 10 & 7 \\
\hline $1+$ & 90冈70-100》 & $55 \rrbracket 10-70 \rrbracket$ & $30 \rrbracket 5-40 \rrbracket$ & 24 & 7 & 6 \\
\hline $2+$ & $90 \rrbracket 40-100 \rrbracket$ & $30 \rrbracket 10-35 \rrbracket$ & 30 & 40 & 3 & 1 \\
\hline $3+$ & 85ख70-100》 & - & - & 22 & - & - \\
\hline
\end{tabular}

Table VII Correlations between TTK expressions and clinicopathological parameters 


\begin{tabular}{|c|c|c|c|c|c|}
\hline \multirow[t]{2}{*}{ parameters } & & \multicolumn{2}{|c|}{ TTK expression } & \multirow[t]{2}{*}{$x^{2}$} & \multirow[t]{2}{*}{$P$-value } \\
\hline & & $\begin{array}{l}\text { High } \\
\text { expression }\end{array}$ & $\begin{array}{l}\text { low } \\
\text { expression }\end{array}$ & & \\
\hline Age(years) & & & & 0.498 & 0.480 \\
\hline & $\leq 52$ & $20 \bigotimes 52.6 \% \bigotimes$ & $18 \varangle 47.4 \% \rrbracket$ & & \\
\hline & $\otimes 52$ & $28 \rrbracket 60.0 \% \rrbracket$ & $27 \rrbracket 40.0 \% \rrbracket$ & & \\
\hline Clinical stages & & & & 13.362 & $₫ 0.001$ \\
\hline & $\mathrm{I}-\mathrm{II}$ & $10 \otimes 27.8 \% \rrbracket$ & $26 \varangle 72.2 \% \rrbracket$ & & \\
\hline & III-IV & $38 \rrbracket 66.7 \% \rrbracket$ & $19 \llbracket 33.3 \% \rrbracket$ & & \\
\hline $\begin{array}{l}\text { Lymphatic } \\
\text { metestasis }\end{array}$ & & & & 18.028 & $₫ 0.001$ \\
\hline & with & $35 \otimes 72.9 \% \square$ & $13 \llbracket 27.1 \% \rrbracket$ & & \\
\hline & without & $13 \rrbracket 28.9 \% \bigotimes$ & $32 \varangle 71.1 \% \square$ & & \\
\hline ascites & & & & 24.029 & $₫ 0.001$ \\
\hline & with & $40 \otimes 72.7 \% \square$ & $15 \llbracket 27.3 \% \rrbracket$ & & \\
\hline & without & $8 \rrbracket 21.1 \% \rrbracket$ & $30 \otimes 78.9 \% \rrbracket$ & & \\
\hline Histoloogical & & & & 19.905 & $\otimes 0.001$ \\
\hline & $\begin{array}{l}\text { Intermediately and well } \\
\text { differentiated }\end{array}$ & $10 \rrbracket 25.0 \% \rrbracket$ & $30 \otimes 75.0 \% \rrbracket$ & & \\
\hline & Poorly differentiated & $38 \otimes 71.7 \% \square$ & $15 \varangle 28.3 \% \rrbracket$ & & \\
\hline Pathological type & & & & 4.055 & 0.044 \\
\hline & Serous & $38 \otimes 58.5 \% \square$ & $27 \rrbracket 41.5 \% \rrbracket$ & & \\
\hline & Non-serous & $10 \otimes 35.7 \% \bigotimes$ & $18 \rrbracket 64.3 \% \rrbracket$ & & \\
\hline $\begin{array}{l}\text { Whether to give } \\
\text { birth }\end{array}$ & & & & 0.173 & 0.678 \\
\hline & with & $40 \rrbracket 52.6 \% \bigotimes$ & $36 \rrbracket 47.4 \% \rrbracket$ & & \\
\hline & without & $8 \otimes 47.1 \% \bigotimes$ & $9 \llbracket 52.9 \% \rrbracket$ & & \\
\hline Distant metastasis & & & & 37.675 & $₫ 0.001$ \\
\hline & with & $42 \bigotimes 79.2 \% \bigotimes$ & $11 \rrbracket 20.8 \% \rrbracket$ & & \\
\hline & without & $6 \otimes 15.0 \% \rrbracket$ & $34 \llbracket 85.0 \% \rrbracket$ & & \\
\hline CA125ه0-35】 & & & & 8.516 & 0.004 \\
\hline
\end{tabular}




\begin{tabular}{|c|c|c|c|c|c|}
\hline & Normal & $8 囚 28.6 \% \rrbracket$ & $20 \bigotimes 71.4 \% \rrbracket$ & & \\
\hline & Elevated & 40囚61.5\%》 & $25 \bowtie 38.5 \% \rrbracket$ & & \\
\hline HE4『0-140》 & & & & 5.925 & 0.015 \\
\hline & Normal & 10ه33.3\%》 & $20 \otimes 66.7 \% \rrbracket$ & & \\
\hline & Elevated & $38 \bowtie 60.3 \% \rrbracket$ & $25 \llbracket 39.7 \% \rrbracket$ & & \\
\hline
\end{tabular}

\section{Table VIII Multivariate analysis of ovarian cancer}

\begin{tabular}{|c|c|c|c|c|c|c|c|}
\hline \multirow[t]{2}{*}{ parameters } & \multirow[t]{2}{*}{$b$} & \multirow[t]{2}{*}{ S.E } & \multirow[t]{2}{*}{$\begin{array}{l}\text { Wald } \\
\chi 2\end{array}$} & \multirow[t]{2}{*}{$\mathrm{P}$} & \multirow[t]{2}{*}{ OR } & \multicolumn{2}{|c|}{$\begin{array}{l}\text { OR } 95 \% \text { of the } \\
\mathrm{Cl}\end{array}$} \\
\hline & & & & & & $\begin{array}{l}\text { upper } \\
\text { limit }\end{array}$ & $\begin{array}{l}\text { lower } \\
\text { limit }\end{array}$ \\
\hline Distant transfer (yes) & 3.07 & 0.55 & 30.41 & 0.00 & 21.63 & 7.25 & 64.52 \\
\hline Lymph node metastasis (yes) & 1.89 & 0.46 & 16.73 & 0.00 & 6.62 & 2.67 & 16.39 \\
\hline Clinical Phases (Phase I-II) & -1.64 & 0.46 & 12.50 & 0.00 & 0.19 & 0.07 & 0.48 \\
\hline $\begin{array}{l}\text { degree of differentiation (Intermediately } \\
\text { and well differentiated) }\end{array}$ & -2.02 & 0.47 & 18.17 & 0.00 & 0.13 & 0.052 & 0.33 \\
\hline CA125(Elevated囚 & 1.38 & 0.49 & 8.00 & 0.005 & 4.00 & 1.53 & 10.49 \\
\hline HE4هElevated》 & 1.11 & 0.46 & 5.71 & 0.17 & 3.04 & 1.22 & 7.56 \\
\hline Abdominal water (yes) & 2.51 & 0.50 & 24.40 & 0.00 & 12.30 & 4.54 & 33.31 \\
\hline
\end{tabular}

Figures 


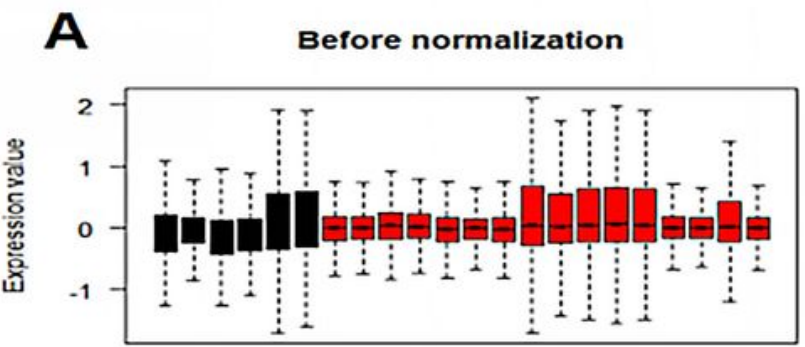

B
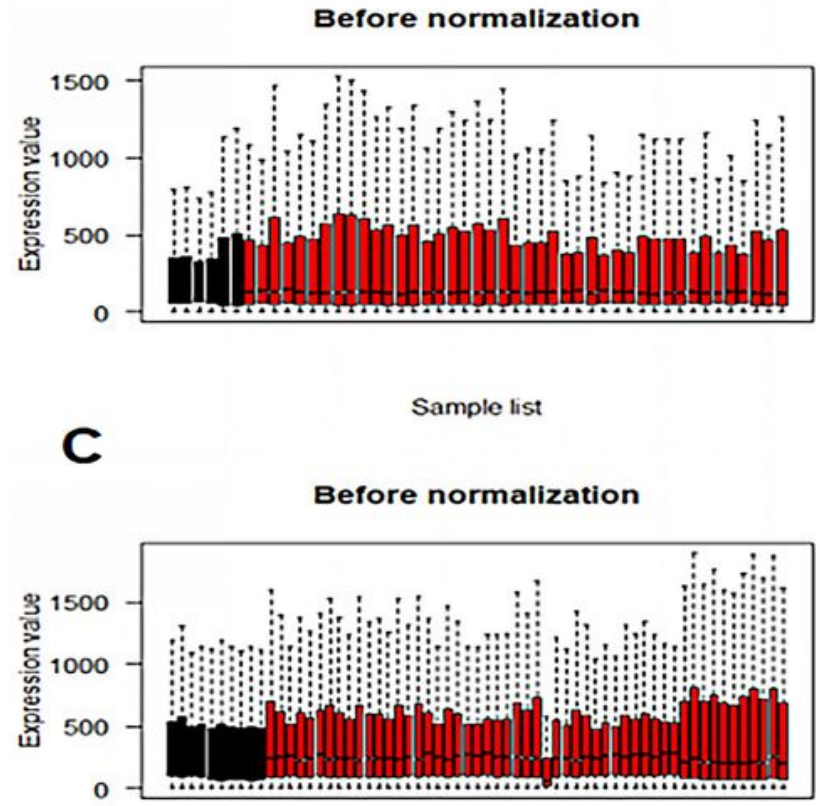

Sample list

D

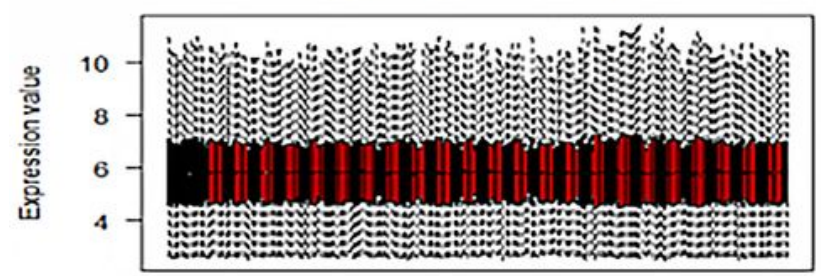

Sample list

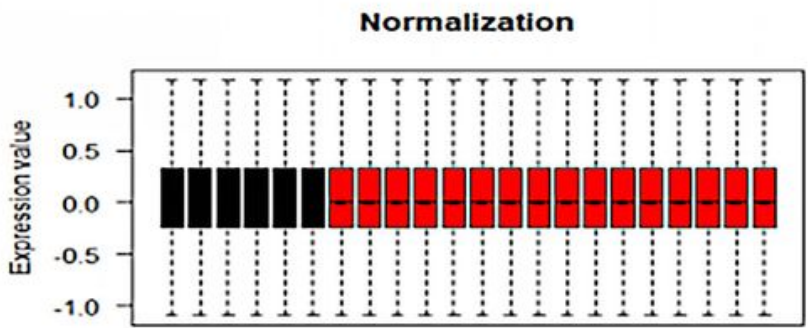

Sample list

Normalization

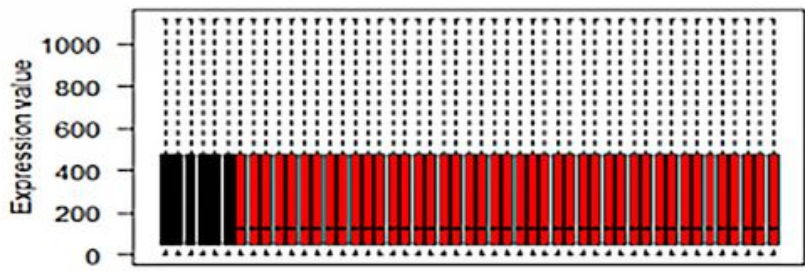

Sample list

Normalization

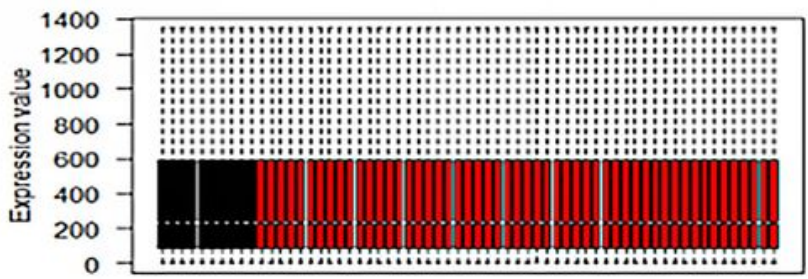

Sample list

Normalization

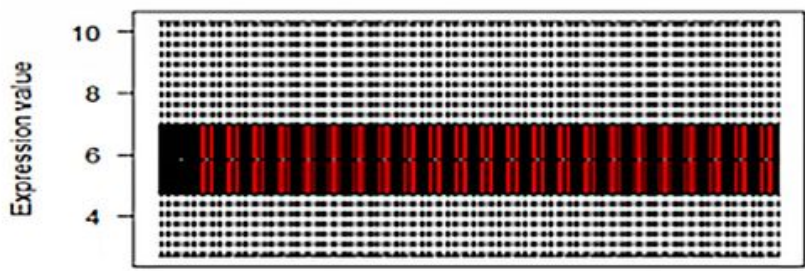

Sample list

Figure 1

Standardization of gene expression. (A)The standardization of GSE54388 data,(B)the standardization of GSE27651 data,(C) the standardization of GSE18520 data,and(D)the standardization of GSE27651 data. The red bar represents the ovarian cancer samples expression value,and the black bar represents the healthy tissue samples expression value. 

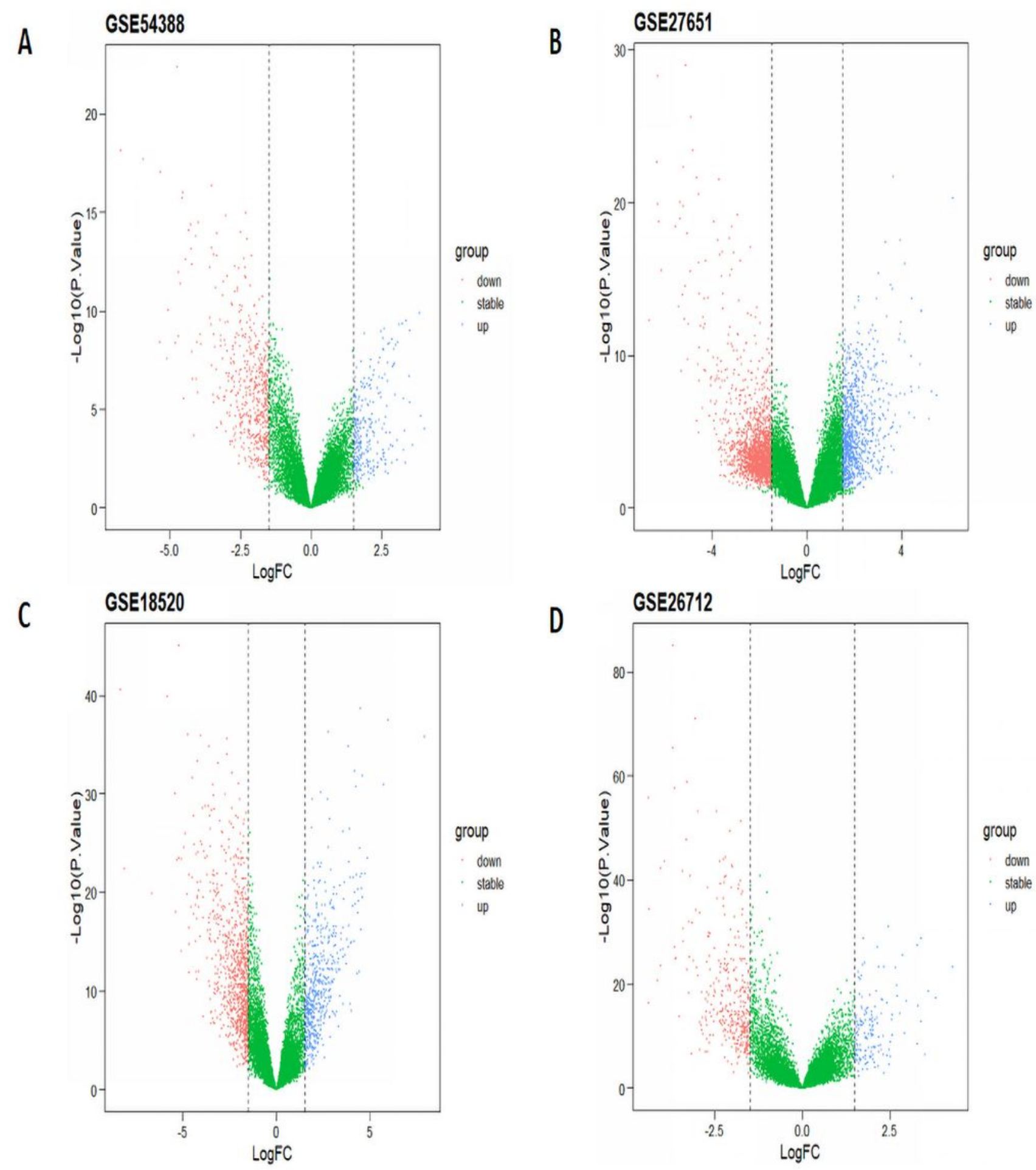

Figure 2

Volcano plot of gene expression profile data in ovarian cancer samples and normal ones.(A)Volcano plot of GSE54388,(B)Volcano plot of GSE27651,(C)Volcano plot of GSE18520,(D)Volcano plot of GSE26712.Blue plots represented lower expression levels genes with fold change $\geq 1.5$ 『red plots represented higher expression levels genes with fold change $\leq 1$.5.Green plots represented the rest genes with no significant expression change. 


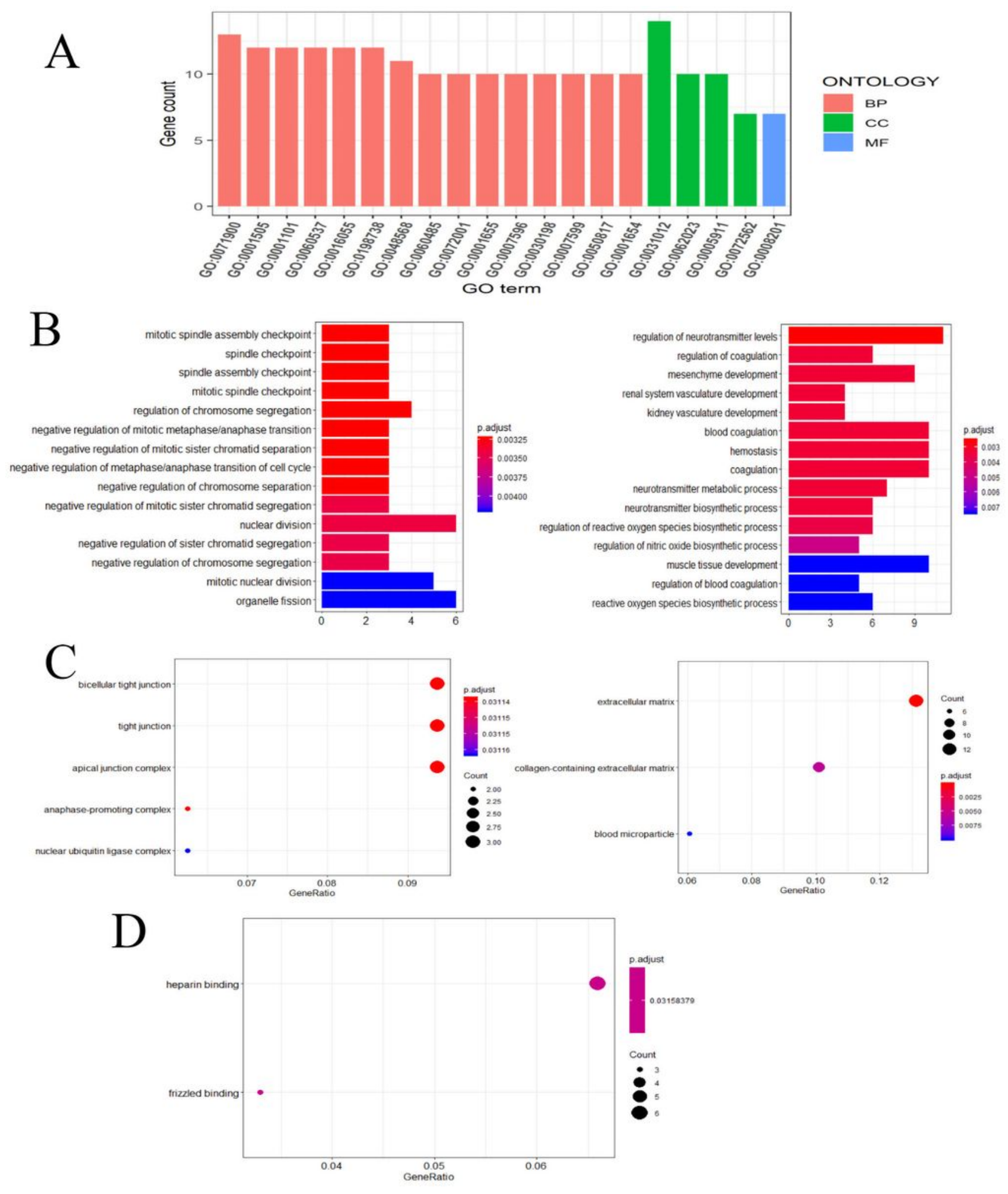

Figure 3

GO enrichment analysis of DEGs in ovarian cancer. (A) GO analysis divided DEGs into three functional groups:biological process (BP),cellular composition(CC)and molecular function(MF).(B)There are two barplots,the left side is the top15 of biological process of up-regulated DEGs,the right side is the top 15 of down-regulated DEGs.(C) There are two dotplots,the left side is the cellular composition of up-regulated 
DEGs,the right side is the cellular composition of down-regulated DEGs. (D) This is the molecular function of down-regulated DEGs and the up-regulated DEGs are not significantly enriched.

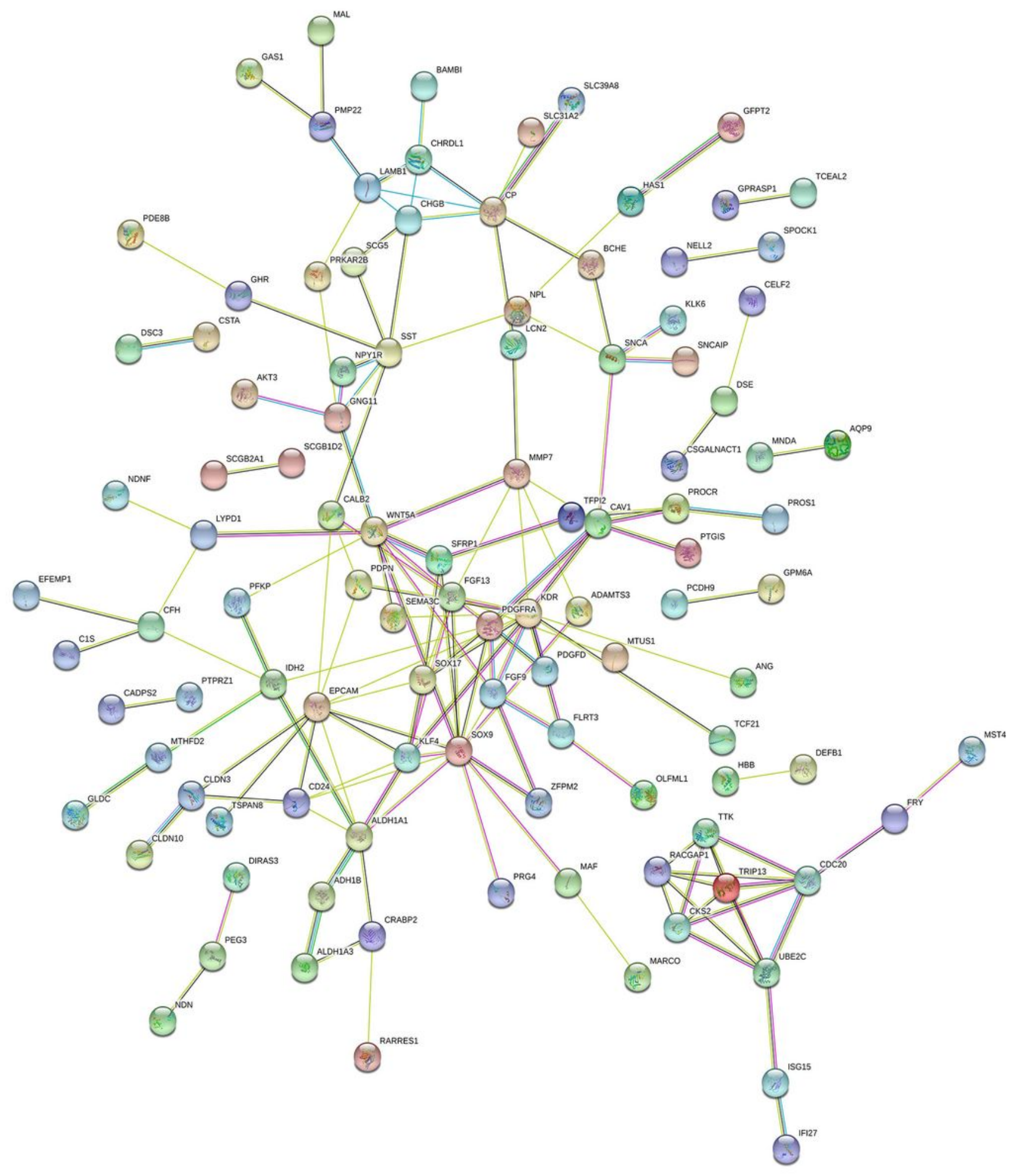

\section{Figure 4}

Circles represent genes, lines represent the interaction of proteins between genes, and the results within the circle represent the structure of proteins. Line color represents evidence of the interaction between the proteins. 
A
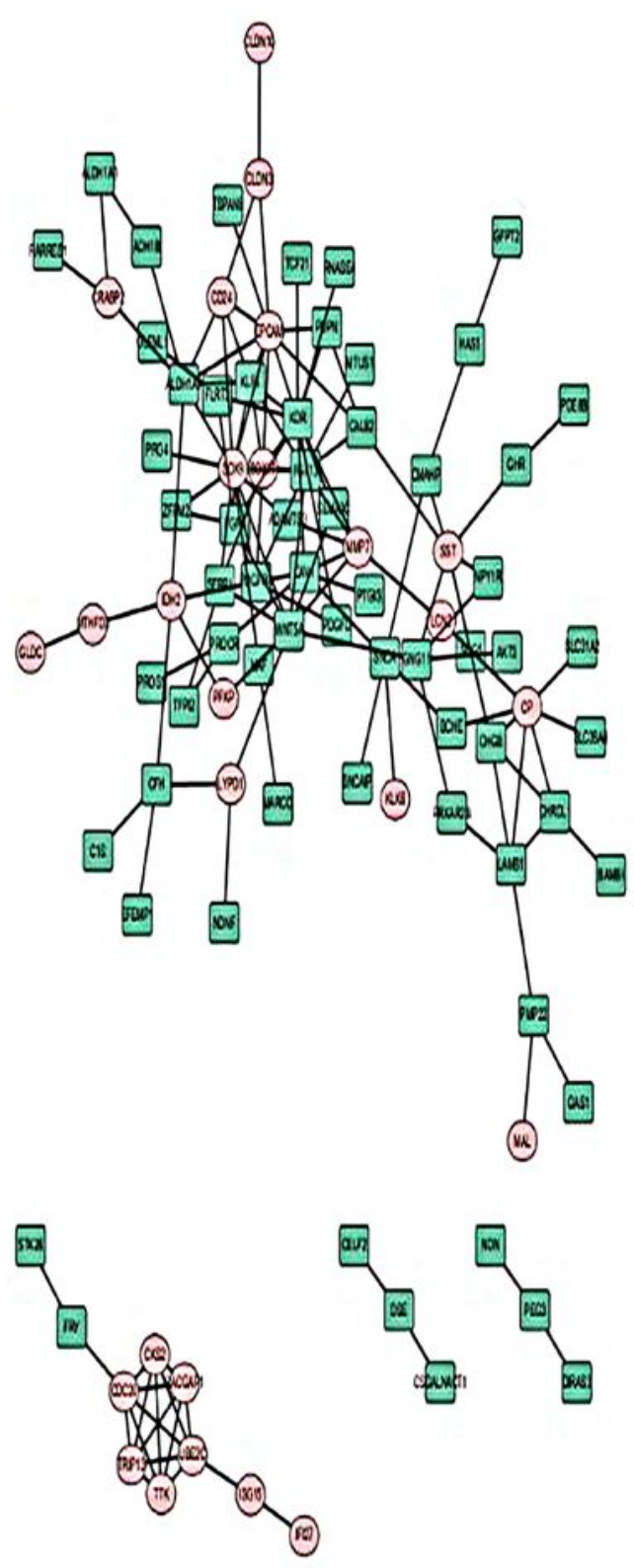

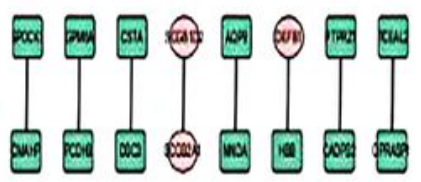

B
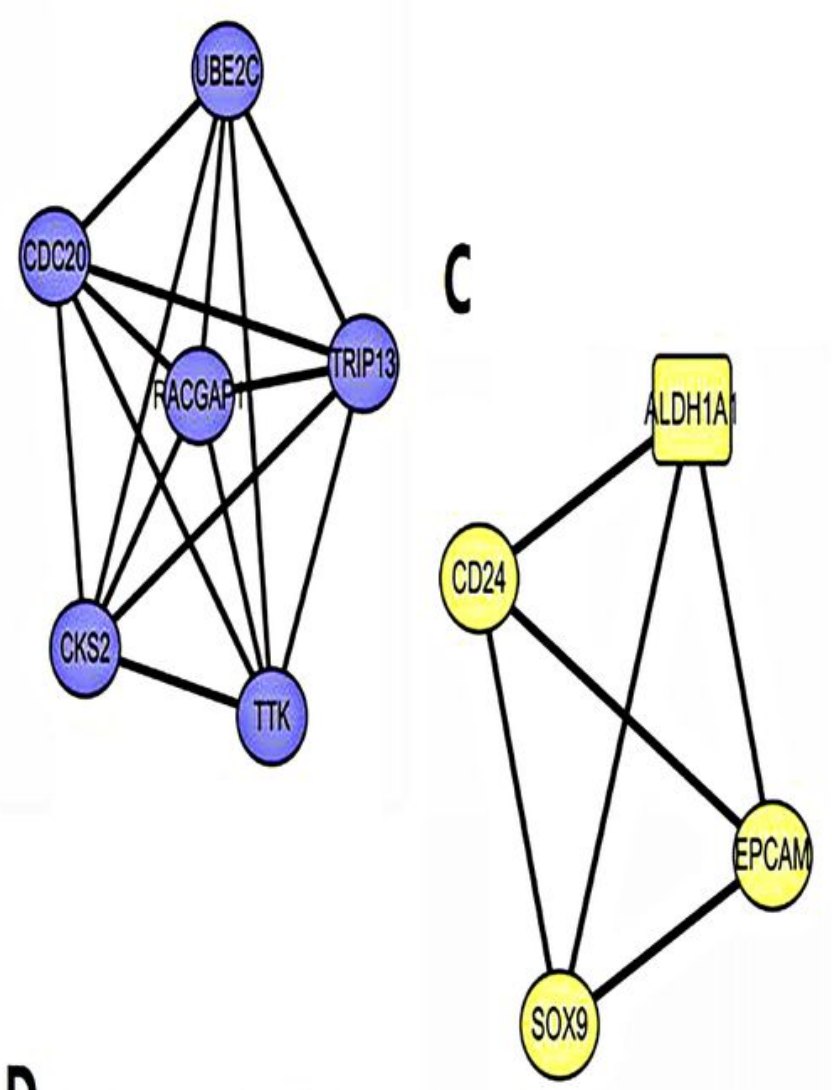

D

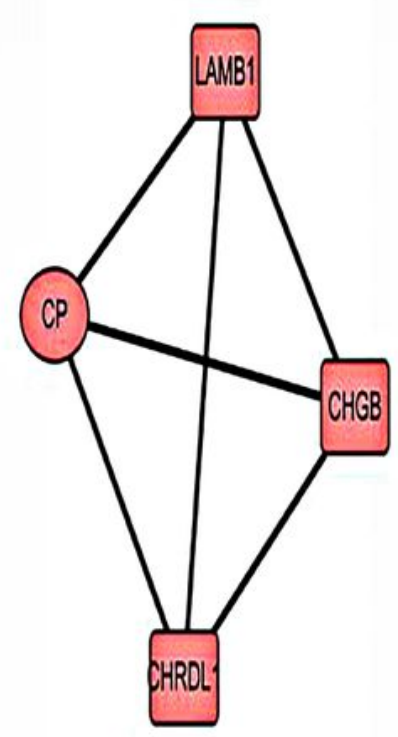

Figure 5

(A)PPI network with 106 DEGs. The nodes meant proteins,the edges meant the interaction of proteins;green rectangle meant down-regulated DEGs and pink circle meant up-regulated DEGs. Module

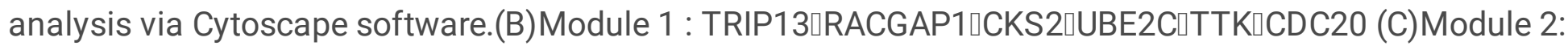

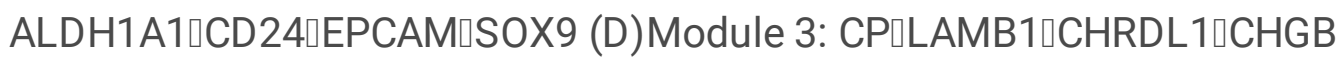



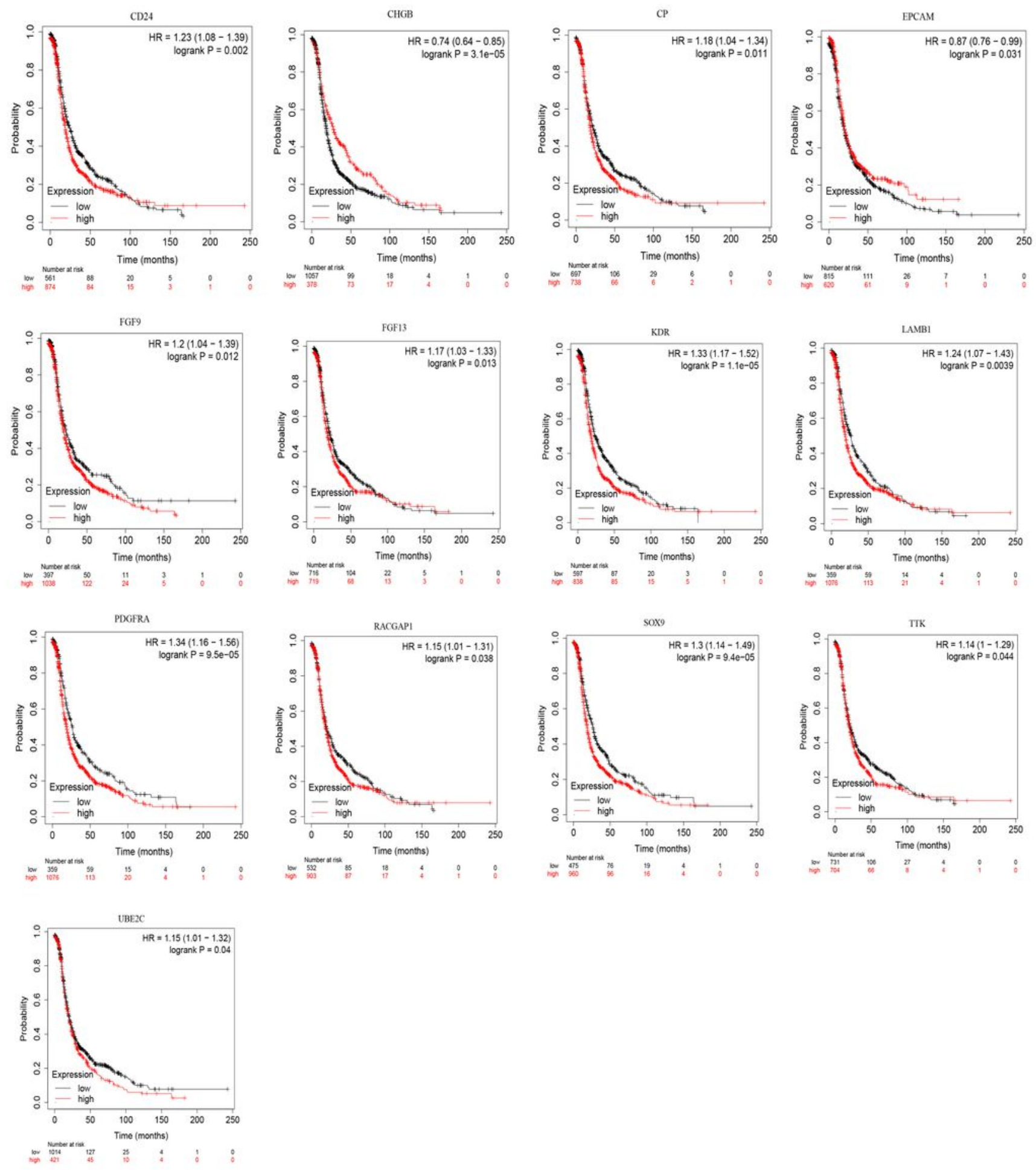

\section{Figure 6}

The prognosis of 20 hub genes was analyzed with Kaplan-Meier Plotter, and 13 genes had significantly poor survival rate $(\mathrm{P}<0.05)$. 

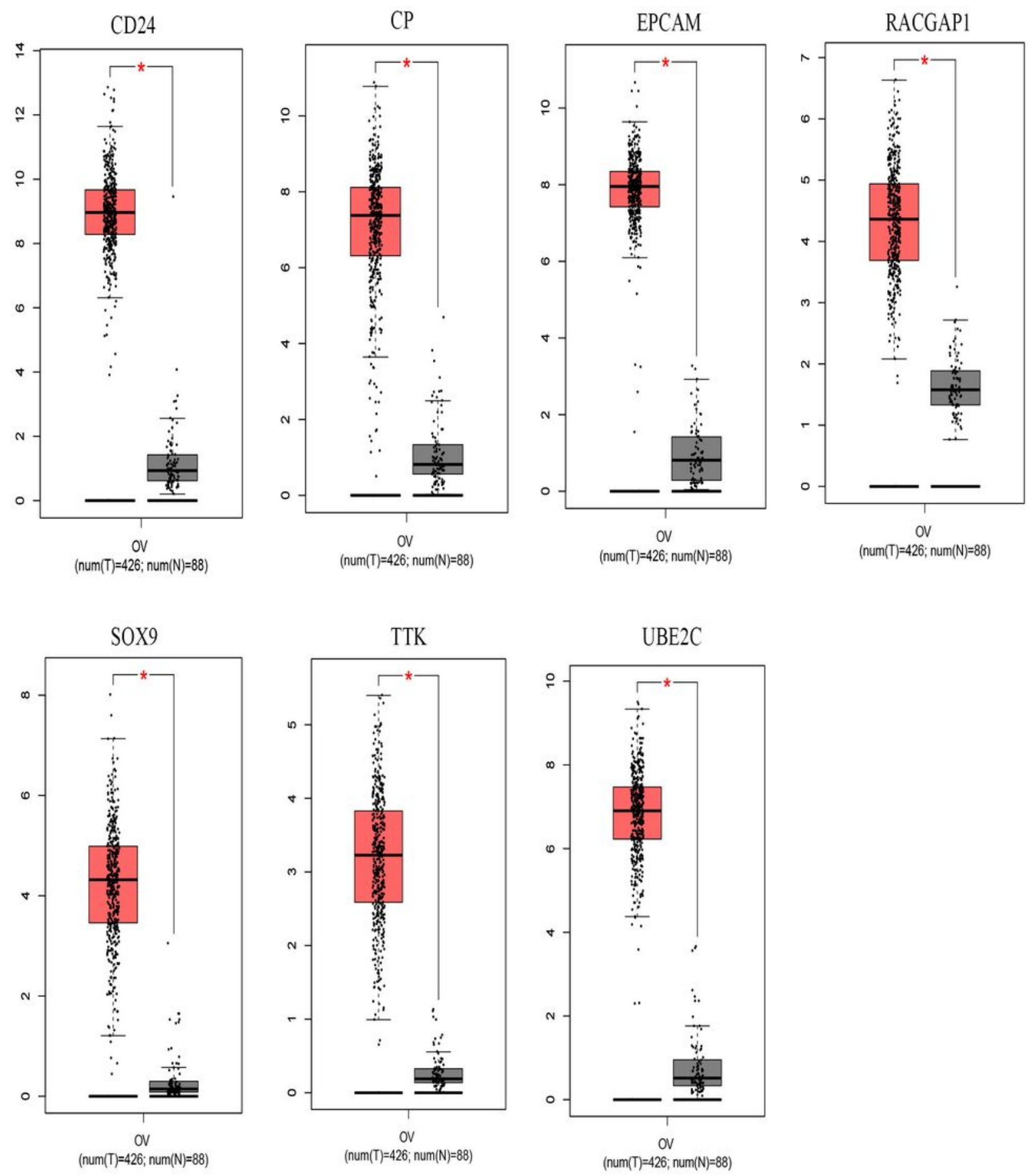

Figure 7

An analysis of gene expression levels on the GEPIA website found that 7 of 13 genes with poor prognosis were significantly expressed in ovarian cancer samples $(P<0.01)$. The red and grey boxes represent ovarian cancer and normal tissues respectively. 

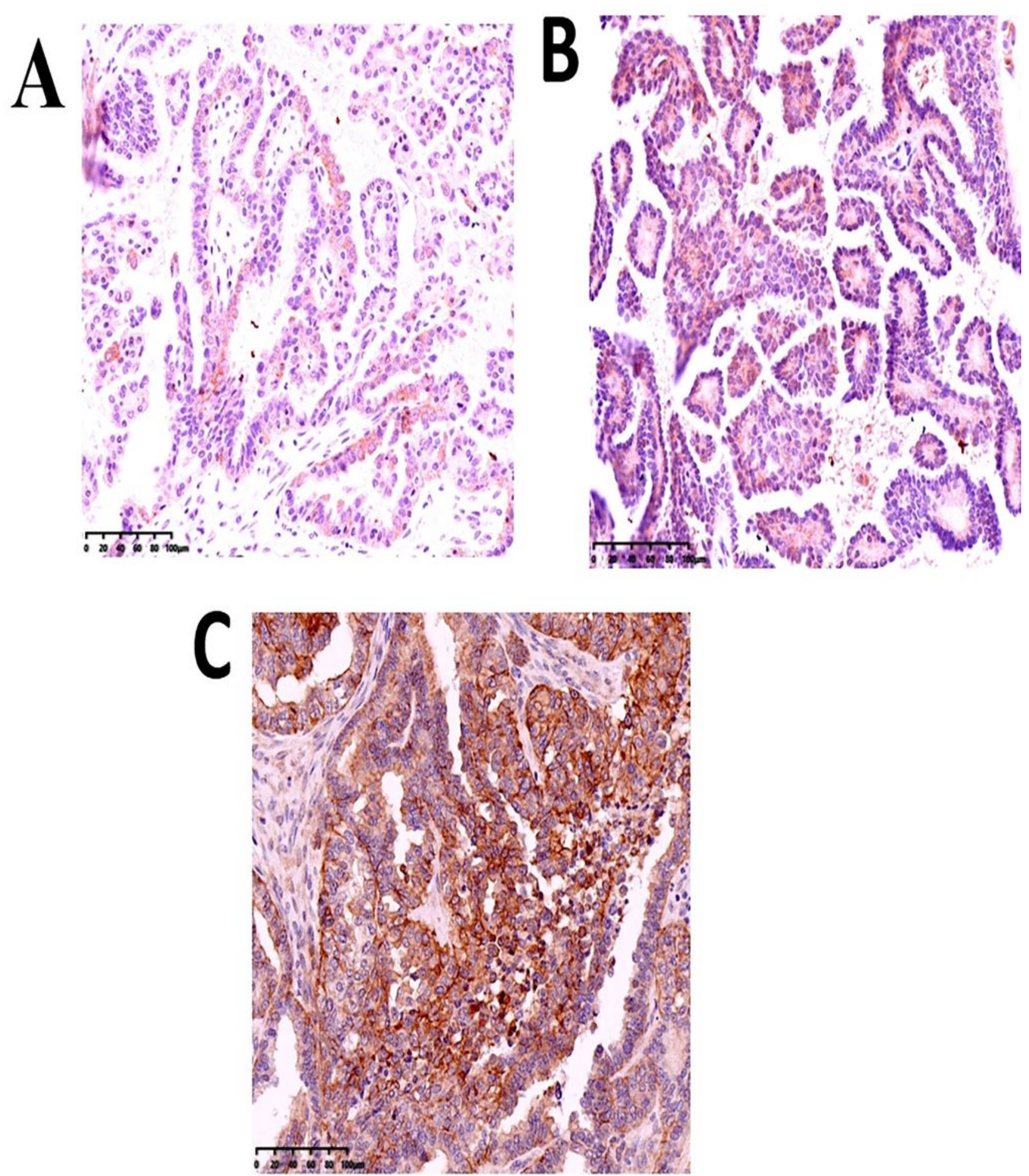

\section{Figure 8}

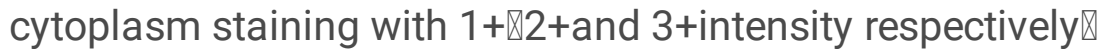




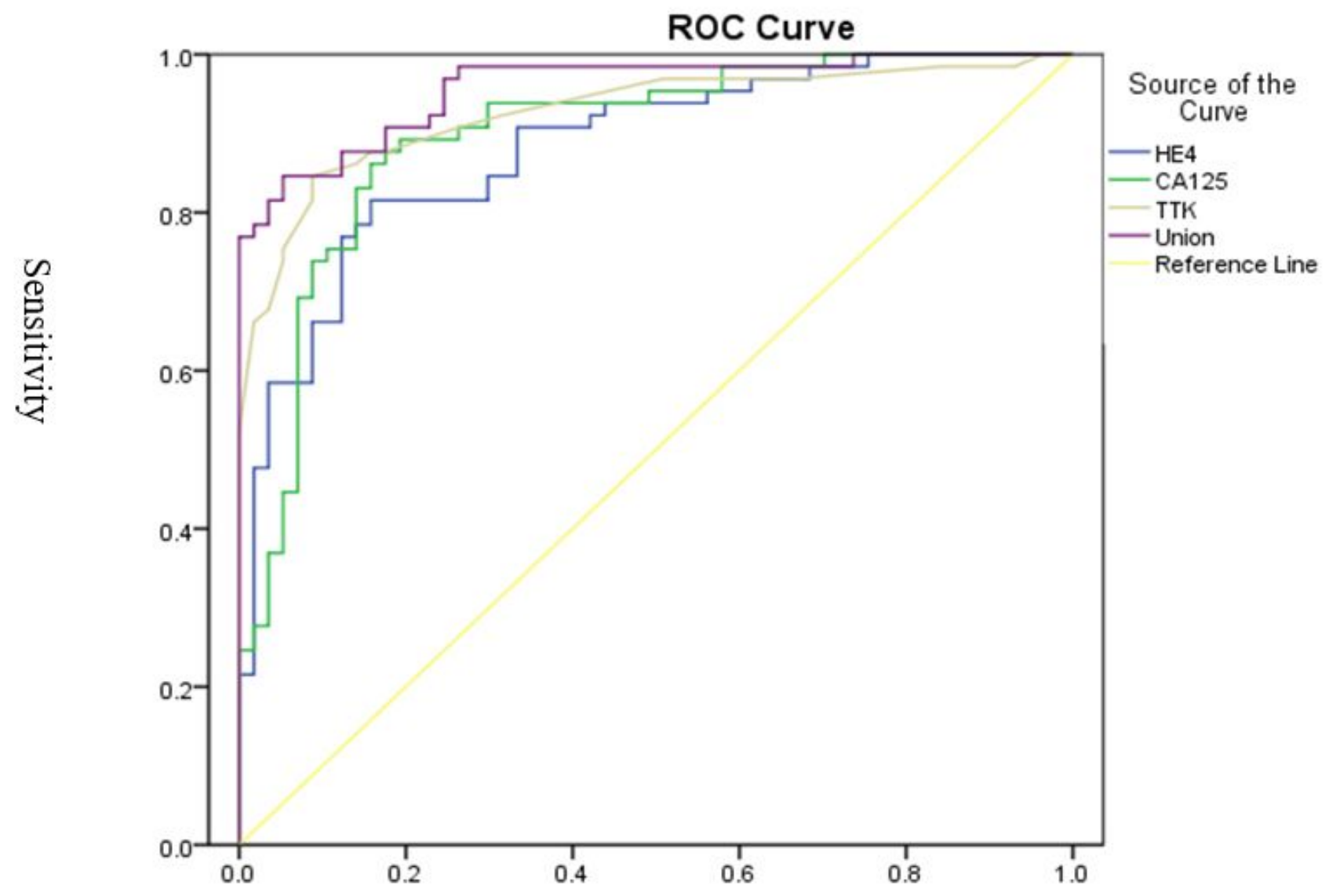

1- specificity

\begin{tabular}{|l|l|l|l|l|}
\hline & HE4 & CA125 & TTK & Union \\
\hline $\begin{array}{l}\text { Area under the } \\
\text { curve }\end{array}$ & 0.882 & 0.899 & 0.927 & 0.958 \\
\hline
\end{tabular}

Figure 9

ROC 